\title{
PASSIVE AND TRANSPASSIVE BEHAVIOUR OF ALLOY 31 IN A HEAVY BRINE LiBr SOLUTION
}

\author{
Fernández-Domene, R.M., Blasco-Tamarit, E., García-García, D.M., García- \\ Antón, J. * \\ Ingeniería Electroquímica y Corrosión (IEC). Departamento de Ingeniería Química y \\ Nuclear. ETSI Industriales. Universitat Politècnica de València. Camino de Vera s/n, \\ 46022 Valencia, Spain.
}

Tel.34-96-387 76 32, Fax.34-96-387 76 39, e-mail: jgarciaa@iqn.upv.es

\begin{abstract}
The passive and transpassive behaviour of Alloy 31, a highly-alloyed austenitic stainless steel (UNS N08031), has been investigated in a LiBr heavy brine solution (400 $\mathrm{g} / \mathrm{l})$ at $25^{\circ} \mathrm{C}$ using potentiostatic polarisation combined with electrochemical impedance spectroscopy and Mott-Schottky analysis. The passive film formed on Alloy 31 has been found to be $p$-type and/or $n$-type in electronic character, depending on the film formation potential. The thickness of the film formed at potentials within the passive region increases linearly with applied potential. The film formed at transpassive potentials is thinner and more conductive than the film formed within the passive region. These observations are consistent with the predictions of the Point Defect Model for passive and transpassive films on metals and alloys.
\end{abstract}

Keywords: stainless steel; passive film; transpassivity; EIS; Mott-Schottky 


\section{INTRODUCTION}

Energy demand for refrigeration and air-conditioning systems has been increasing in recent years, due to the demand of higher comfort conditions inside buildings [1-4]. This has led to a widespread use of air conditioning systems based on compression technology, with the associated negative impact on the environment (ozone layer depletion and $\mathrm{CO}_{2}$ emissions). Refrigeration absorption systems which use highly concentrated lithium bromide solutions as absorbent ( $\mathrm{LiBr}$ absorbs the water vapour coming from the evaporator) are a suitable alternative to compression systems. However, lithium bromide/water absorption systems also have some drawbacks, such as the severe corrosion problems on metallic components due to the aggressiveness of bromide ions [5-12]. Therefore, highly corrosion resistant materials have been developed for the construction of LiBr absorption machines, such as Alloy 31 (UNS N08031) [13], a highly alloyed austenitic stainless steel that consists of much larger amounts of alloying elements $(26.75 \% \mathrm{Cr}, 31.85 \% \mathrm{Ni})$ in comparison with the typical $18 \% \mathrm{Cr}, 10-12 \% \mathrm{Ni}$ austenitic stainless steels.

The enhanced corrosion resistance of Alloy 31 is attributed to the formation of a thin and stable oxide film on its surface, known as passive film. Therefore, passivity is defined as the decrease in the corrosion rate of a metal or alloy resulting from the formation of a thin and tenacious protective film due to the oxidation of the metal. From an engineering point of view, passivity of metals is a phenomenon of utmost importance. The Point Defect Model (PDM) successfully accounts for the properties of the passive state [14-19]. According to the PDM, passive films contain a high concentration of point defects (vacancies and interstitials) and behave as incipient 
semiconductors. The type, concentration and distribution of these vacancies determine the properties of passive films and, as a consequence, the behaviour of metals and alloys against corrosion. Vacancies generate and annihilate at the interfaces, which are normally separated by no more than a few nanometers (passive film thickness). The electric field strength across the film depends on the chemical and electrical properties of the film, and is independent of applied potential and film thickness. The PDM also provides a number of diagnostic criteria that can be used to determine the principal crystallographic defects within the passive film.

The objective of this work is to examine the effect of formation potential on the passive and transpassive behaviour of Alloy 31 in a heavy brine $\mathrm{LiBr}$ solution $(400 \mathrm{~g} / \mathrm{LiBr}$, which is a typical $\mathrm{LiBr}$ concentration inside absorption machines) at $25^{\circ} \mathrm{C}$, using potentiostatic polarisation, EIS measurements and Mott-Schottky analysis

\section{EXPERIMENTAL PROCEDURE}

The material tested was the highly alloyed austenitic stainless steel Alloy 31 (UNS N08031: Cr 26.75 (wt\%), Ni 31.85 (wt\%), Mn 1.50 (wt \%), Si 0.10 (wt\%), Mo 6.60 (wt\%), Cu 1.21 (wt\%), Fe 31.43 (wt \%), S 0.002 (wt \%), P 0.017 (wt \%), C 0.005 (wt\%), N 0.193 (wt\%), provided by ThyssenKrupp VDM. The Alloy 31 electrodes were cylindrically shaped (8-mm in diameter) and covered with a polytetrafluoroethylene (PTFE) coating. The area exposed to the solution was $0.5 \mathrm{~cm}^{2}$. All specimens were wet abraded from 500 to $4000 \mathrm{SiC}$ grit, and finally rinsed with distilled water. The samples were tested in a $400 \mathrm{~g} / 1(4.61 \mathrm{M}) \mathrm{LiBr}$ solution $(\mathrm{pH}=6.80)$, prepared from $\mathrm{LiBr}$ salt $(98$ wt $\%)$, from PANREAC. 
The electrochemical measurements were carried out with an Autolab PGSTAT302N potentiostat. $\mathrm{An} \mathrm{Ag} / \mathrm{AgCl}(3 \mathrm{M} \mathrm{KCl})$ electrode served as the reference electrode and a platinum wire served as the counter electrode. Before the potentiostatic passivation tests, the surface of the samples was initially pretreated cathodically at $-1 \mathrm{~V}_{\mathrm{Ag} / \mathrm{AgCl}}$ for 30 min. Afterwards, the working electrode was polarised at different film formation potentials within the passive region (from $-0.3 \mathrm{~V}_{\mathrm{Ag} / \mathrm{AgCl}}$ to $0.1 \mathrm{~V}_{\mathrm{Ag} / \mathrm{AgCl}}$ ) and within the transpassive region (from $0.15 \mathrm{~V}_{\mathrm{Ag} / \mathrm{AgCl}}$ to $0.4 \mathrm{~V}_{\mathrm{Ag} / \mathrm{AgCl}}$ ) of Alloy 31 for 1 hour to form a steady-state film. Polarisation curves of Alloy 31 in the $400 \mathrm{~g} / \mathrm{l} \mathrm{LiBr}$ solution were presented elsewhere [20]. In these curves, passive and transpassive regions can be observed.

EIS experiments were conducted over a frequency range from $100 \mathrm{kHz}$ to $10 \mathrm{mHz}$ with a $10 \mathrm{mV}$ (peak to peak) signal amplitude. Mott-Schottky plots were subsequently obtained by sweeping the potential from the film formation value in the negative direction with potential steps of $50 \mathrm{mV}$, at a frequency of $5 \mathrm{kHz}$ with an amplitude signal of $10 \mathrm{mV}$. A high scanning rate was used to avoid electroreduction of the passive film and changes in film thickness during the measurements. At a sufficiently high scanning rate, the defect structure within the passive film is "frozen-in", which avoids the defect density from being affected by potential [21-23].

\section{RESULTS AND DISCUSSION}

\section{Potentiostatic passivation tests}


Potentiostatic passivation tests were conducted at several formation potentials within the passive (from -0.3 to $0.1 \mathrm{~V}$ ) and transpassive (from 0.15 to $0.4 \mathrm{~V}$ ) regions of Alloy 31 [20]. As an illustration, Figure 1 shows the current density transients recorded during the potentiostatic passivation tests at $-0.3,-0.1$ and $0.1 \mathrm{~V}$ (within the passive region) and at $0.4 \mathrm{~V}$ (within the transpassive region). Regardless of the applied potential, the current density of Alloy 31 decreases exponentially with time as the film grows on the electrode surface, and eventually reaches a very low steady-state value $\left(i_{s s}\right)$ of the order of $0.1-0.3 \mu \mathrm{A} / \mathrm{cm}^{2}$ after 1 hour of film formation. In the inserts in Figure 1 it can be observed that current density values increase as the applied potential increases, especially at the potential located in the transpassive region. In previous studies [20], a current density peak was observed in the polarisation curves of Alloy 31 in heavy brine $\mathrm{LiBr}$ solutions, before the sharp increase in current density due to the onset of pitting corrosion (Figure 2). This peak has been related to the transpassive dissolution of Crcontaining species. Thus, the higher values of current density obtained at $0.4 \mathrm{~V}$ can be related to the transformation of $\mathrm{Cr}$ oxides and hydroxides to form chemical species in a valence state higher than that in the primary passive film. It is important to remark that at these potentials within the transpassive region, which are lower than the pitting potential [20], the electrode examination revealed no damage on its surface, indicating that the passive film was not destroyed.

The PDM predicts that the steady-state passive current density, $i_{S S}$, contains three components corresponding to the generation and movement of cation interstitials, cation vacancies and oxygen vacancies through the film $[19,24]$. According to this model, $\ln i_{S S}$ will vary linearly with film formation potential, $E_{f}$, provided that cation interstitials, cation vacancies or oxygen vacancies dominate ionic charge transfer 
through the film. A plot of $\ln i_{s s}$ vs $E_{f}$ is shown in Figure 3. Two different zones can be observed in this diagram, corresponding to the passive region (Region I) and to the transpassive region (Region II). In both regions, a linear dependence of $\ln i_{S S}$ on the film formation potential is observed, with the current density increasing with increasing potential, although the slope of the line in Region II $\left(1.423 \mathrm{~V}^{-1}\right)$ is higher than that in Region I $\left(0.803 \mathrm{~V}^{-1}\right)$. The dependence of $\ln i_{S S}$ on the formation potential provides a diagnostic criterion that can be used to identify the dominant charge carriers in the film under steady-state conditions and to indicate the kinetic nature of the processes that generate and annihilate these defects at the interfaces [17]. According to this criterion, a linear $\ln i_{s s}$ vs. $E_{f}$ dependence with positive slope, as is the case in Figure 3, indicates that there is a preponderance of cation vacancies over cation interstitials and oxygen vacancies in the passive film, that is, the majority of the current is carried by cation vacancies. This preponderance is more evident at potentials in the transpassive region (Region II), since additional cation vacancies are produced in this region by the ejection of cations from the passive film into the electrolyte, involving a change in the oxidation state of the ion. In the case of chromium-containing alloys (such as Alloy 31), the cation ejection from the passive film takes place via the following reaction [24-26]:

$$
\mathrm{Cr}_{\mathrm{Cr}}+4 \mathrm{H}_{2} \mathrm{O} \rightarrow \mathrm{CrO}_{4}^{2-}+\mathrm{V}_{\mathrm{Cr}}^{3^{\prime}}+8 \mathrm{H}^{+}+3 \mathrm{e}^{\prime}
$$

Notice that the Kroger-Vink notation is used in eq. (2) to describe the various species in the system, with $\mathrm{Cr}_{\mathrm{Cr}}$ and $\mathrm{V}_{\mathrm{Cr}}{ }^{3}$ indicating a $\mathrm{Cr}(\mathrm{III})$ cation in a normal site on the cation sub-lattice and a cation vacancy on the same sub-lattice of the passive film, respectively. Reaction (2) leads to enhanced cation transmission through the passive film, and hence to a higher current density [24]. As mentioned above, the reaction in eq. 
(2) does not involve the destruction of the passive film, since it occurs at potentials lower than the pitting potential, $E_{p}$, before the onset of stable pitting corrosion [20].

For cation vacancy conducting films, the PDM predicts that the $\ln i_{S S}$ vs $E_{f}$ relationship within the passive range has the form:

$$
i_{S S}=\delta F k_{c a t}^{0} \exp \left(\alpha_{c a t} \alpha \delta \gamma E_{f}\right) \exp \left(\alpha_{c a t} \beta \delta \gamma p H\right)
$$

where $\delta$ is the charge of the cation ejected from the passive film ( 3 in the case of $\mathrm{Cr}^{3+}$ ), $F$ is Faraday's constant $\left(96485.34 \mathrm{C} \mathrm{mol}^{-1}\right), k_{c a t}^{0}$ and $\alpha_{\text {cat }}$ are the standard rate coefficient and the transfer coefficient, respectively, for the cation ejection reaction at the passive film/electrolyte interface $\left(\mathrm{Cr}_{\mathrm{Cr}} \rightarrow \mathrm{Cr}^{3+}+\mathrm{V}_{\mathrm{Cr}}{ }^{3}\right), \alpha$ is the polarizability of the passive film/electrolyte interface (the dependence of the potential drop across the passive film/electrolyte interface, $\phi_{f / l}$, on the applied potential, $\left.E_{f}\right), \gamma=F / R T$ and $\beta$ is the dependence of the potential drop across the film/electrolyte interface, $\phi_{f / e}$, on $\mathrm{pH}$.

According to eq. (3), a plot of $\ln i_{S S}$ vs. $E_{f}$ in the passive region should be linear with a slope of $\alpha_{\text {cat }} \alpha \delta \gamma$. With $\alpha=0.7$ [24-26], $\delta=3$ and $\gamma=39.32 \mathrm{~V}^{-1}$, the transfer coefficient for the cation ejection reaction at the passive film/electrolyte interface, $\alpha_{c a t}$, can be calculated from the slope $\left(0.803 \mathrm{~V}^{-1}\right)$ in the passive region (Region $\left.\mathrm{I}\right)$, yielding $\alpha_{\text {cat }}=$ 0.01. Low transfer coefficient values have usually been found for passive films on iron and $\mathrm{Fe}-\mathrm{Cr}$ alloys $[25,27,28]$. Since the transfer coefficient is a measure of the location of the transition state relative to the stable states, the rather small value of $\alpha_{c a t}$ indicates that charge separation is not highly developed in the transition state for the cation ejection reaction at the passive film/electrolyte interface, that is, the transition state only occurs at a small displacement of the cation from its normal site within a cation vacancy 
in the passive film surface $[29,30]$. From the intercept at $0.0 V_{S H E}$ of the straight line in Region I $\left(\ln \delta F k_{c a t}^{0}+\alpha_{c a t} \beta \delta \gamma p H\right)$, the value of $k_{c a t}^{0}$ can be calculated. With $\mathrm{pH}=6.80$ and $\beta=-0.005 \mathrm{~V}$ [24-26], the standard rate coefficient for the cation ejection reaction at the film/electrolyte interface gives a value of $k_{c a t}^{0}=2.95 \cdot 10^{-13} \mathrm{~mol} \mathrm{~s}^{-1} \mathrm{~cm}^{-2}$.

\section{EIS measurements}

Electrochemical impedance spectra were measured at different formation potentials in the passive and transpassive regions. By way of illustration, Nyquist and Bode-phase plots are shown in Figure 4 at $-0.3,-0.1,0.1$ and $0.4 \mathrm{~V}$. In all cases, EIS diagrams exhibit a typical passive state shape characterised by high impedance values with phase angle values close to 90 degrees, suggesting that a highly stable film formed on all the electrodes [31-34]. There are no differences between the EIS spectra at the potentials within the passive region $(-0.3,-0.1$ and $0.1 \mathrm{~V})$. However, at $0.4 \mathrm{~V}$, the EIS spectrum shows that impedance in the transpassive region is significantly lower than in the passive region. Besides, the values for the phase angle are slightly lower at $0.4 \mathrm{~V}$. Assuming that the high impedance values obtained in the passive region are due to the passive film, the reduction in impedance within the transpassive region is consistent with a loss of protectiveness against corrosion. In fact, transpassive dissolution of the alloying elements such as $\mathrm{Cr}$ results in their depletion in the passive film, which is closely related to the passive film breakdown [35].

The stability of the system is crucial for the validity of EIS measurements. KramersKronig (K-K) transforms can be used as an independent validity check of the impedance data (that is, compliance of the system with the constraints of the Linear Systems Theory (LST)). Kramers-Kronig transforms have been applied to the 
experimental impedance data by transforming the real axis into the imaginary axis and the imaginary axis into the real axis and then comparing the transformed quantities to their respective experimental data. Typical Kramers-Kronig transforms of the impedance data obtained at $-0.1 \mathrm{~V}$ are displayed in Figure 5. It can be seen that the K-K transforms are similar, especially at low frequencies, following the same trend as the experimental values. $\mathrm{K}-\mathrm{K}$ transforms demonstrate that the system (Alloy $31 / \mathrm{LiBr}$ ) remains stable during the measurement time. This condition is necessary for the analysis of the data in terms of electrical analogues.

The equivalent electric circuit used to interpret EIS spectra of anodically formed passive films is shown in Figure 6. In this equivalent circuit, $R_{S}$ represents the electrolyte resistance, $R_{1}$ and $C P E_{1}$ correspond to the charge transfer resistance and the capacitance of the passive film/electrolyte interface, respectively, and $Z_{W}$ is a Warburg component, which has been used to interpret the transport of vacancies within the passive film, in the frame of the Point Defect Model [14, 16, 36-38]. The Warburg impedance is represented by means of an Open-Boundary Finite Length Diffusion element (OFLD) [37, 39-46], which models dimensional diffusion through a layer of finite thickness with absorbing boundary condition. The equation of the OFLD element is [39-46]:

$$
Z_{W}(O F L D)=\frac{R_{W} \tanh (B \sqrt{j \omega})}{B \sqrt{j \omega}}
$$

where $B=\delta /(D)^{1 / 2}, D$ is the diffusion coefficient of vacancies, $\delta$ is the diffusion layer thickness and $R_{W}$ is the Warburg resistance. 
A constant-phase element (CPE) representing a shift from the ideal capacitor has been used instead of the capacitance itself. The impedance of a constant-phase element is defined as:

$$
Q=Z_{C P E}=\left[C(j \omega)^{n}\right]^{-1}
$$

where $n$, defined as a CPE power, is an adjustable parameter that lies between -1 and 1 . For $n=1$ the CPE describes an ideal capacitor, and for $n=0$ the CPE is an ideal resistor. When $n=0.5$ the $\mathrm{CPE}$ represents Warburg impedance with diffusional character and for $0.5<n<1$ the CPE describes a frequency dispersion of time constants due to local heterogeneities in the dielectric material. A pure inductance yields $n=-1$.

The CPE used in the equivalent electric circuit of Figure 6 has been converted into a pure capacitance $(C)$ through equation $[28,31,47]$ :

$$
C=Q^{1 / n}\left(R_{S}{ }^{-1}+R_{1}^{-1}\right)^{(n-1) / n}
$$

where $Q=\mathrm{Z}_{\mathrm{CPE}}$ (eq. (5)).

The parameters of the equivalent circuit of Figure 6 obtained from the fitting procedure are shown in Table 1. In the passive region, the charge transfer resistance, $R_{l}$, varies with film formation potential, increasing significantly within the passive range. This shows a slower rate of reactions taking place at the passive film/electrolyte interface, 
indicating that the passive films formed at higher passive potentials are more protective than those formed at lower passive potentials. The interfacial capacitance, $C_{l}$, is almost constant in this region. The values of the exponent $n_{1}$ are between $0.93-0.94$ in the passive region, indicating a considerable homogeneity of the passive film surface. The Warburg resistance, $R_{W}$, is non-sensitive to film formation potential within the passive region, because defect transport is primarily due to migration under the influence of the electric field and the field strength is postulated (in the PDM) to be independent of the applied potential $[29,48]$.

In the transpassive region, $R_{l}$ decreases and $C_{l}$ increases slightly at $0.4 \mathrm{~V}$, which suggest worse protective properties of the films formed at high potentials. Furthermore, the Warburg impedance, $R_{W}$, is potential dependent, decreasing significantly as formation potential becomes more positive. The decrease of $R_{W}$ could be explained by the progressive transformation of the compact passive film into a porous transpassive film [29], which forms by the oxidative ejection of $\mathrm{Cr}$ (III) from the passive film to form $\mathrm{Cr}(\mathrm{VI})$, according to eq. (2); the values of the exponent $n_{1}$, which are lower in the transpassive region than in the passive region, support the formation of a porous film.

\section{Capacitance results}

The electrochemical capacitance of the passive film/electrolyte interface was measured as a function of the applied potential to assess the semiconducting properties of the passive films formed on Alloy 31. Since the space charge region developed in the passive film and the Helmholtz layer can be considered as two capacitors in series, the measured capacitance of the film/electrolyte interface can be written as $[49,50]$ : 
where $C_{S C}$ is the capacitance of the space charge layer and $C_{H}$ the capacitance of the Helmholtz layer.

It is important to remark that capacitance is frequency dependant [51-56]. Several causes for the frequency dispersion have been proposed: (i) a non-uniform distribution of point defects through the passive film $[52,55,57]$; (ii) the contribution of surface states to the capacitance response (adsorption of anions, e.g. chlorides, or other species) $[52,55]$; (iii) the ionic part of the space charge layer, which gives a contribution only at low frequencies due to the low ionic mobility, particularly in heavily doped materials where the space charge region is very thin (passive films generally satisfy these requirements) $[52,54,58]$; (iv) dielectric relaxation phenomena which occur throughout the space charge layer and the Helmholtz layer [50, 52, 53, 55]; (v) an amorphous and strongly disordered semiconductor nature of passive films, characterised by a high density of localised states between the valence and the conduction band and whose charging leads to a strong frequency dependent capacitance behaviour $[51,52,57,58]$; (vi) presence of deep donor states $[52,53,58]$.

Figure 7 shows the capacitance-potential curves obtained at $-0.1 \mathrm{~V}$ and at different frequencies. It can be observed that there is a strong frequency dependence at low frequencies (capacitance curves shift to higher values with decreasing frequencies), but the capacitance becomes almost independent of frequency at approximately $5 \mathrm{kHz}$. Therefore, a value of $5 \mathrm{kHz}$ has been used in this work to eliminate capacitance dependence on frequency. 
Figure 8 shows the capacitance-potential relationship at a frequency of $5 \mathrm{kHz}$ of the passive film formed at $-0.1 \mathrm{~V}$ (passive region) and at $0.4 \mathrm{~V}$ (transpassive region). These curves are representative of the results obtained at the different applied potentials in both passive and transpassive regions.

In the case of the film formed at $0.4 \mathrm{~V}$, the capacitance falls continuously from 0.4 to $0.4 \mathrm{~V}$. The initial higher capacitance value can be attributed to either the strong dependence of the current density on potential in the transpassive region (see Figure 3) or the development of an inversion layer in the passive film so it becomes conductive $[51,52]$. In the potential range from $-0.4 \mathrm{~V}$ to $-1.3 \mathrm{~V}$, both diagrams have a similar shape. Below $-0.4 \mathrm{~V}$, the capacitance values start rising as a consequence of the reduction of the space charge layer thickness, reaching a maximum value of $20-22 \mu \mathrm{F}$ $\mathrm{cm}^{-2}$ at a potential around $-0.85 \mathrm{~V}$. In this narrow potential region (the flat-band potential, $\left.E_{F B}\right)$ the contribution of the space charge layer to the measured capacitance is limited and the Helmholtz layer dominates the capacitance response. At potentials more negative than $-0.85 \mathrm{~V}$ the capacitance values decrease as the space charge layer thickens again.

It is usually assumed that the Helmholtz layer capacitance is so large compared with the space charge layer capacitance that the total capacitance measured can be treated as the space charge layer capacitance and the potential drop caused by the applied potential occurs entirely within the space charge region. However, several studies [49, 59] have shown that a significant part of the potential difference at the semiconductor/electrolyte interface extends to the Helmholtz layer in the solution. Therefore, $C_{H}$ should not be 
neglected, particularly in highly doped semiconductors, such as passive films [49, 50]. In this case, the passive film/electrolyte interface can be described by the Mott-Schottky expressions $[49,50,52]$ :

$$
\begin{array}{ll}
\frac{1}{C^{2}}=\frac{1}{C_{H}^{2}}+\frac{2}{\varepsilon \varepsilon_{0} e N_{D}}\left(E-E_{F B}-\frac{k T}{e}\right) & \text { n-type } \\
\frac{1}{C^{2}}=\frac{1}{C_{H}^{2}}-\frac{2}{\varepsilon \varepsilon_{0} e N_{A}}\left(E-E_{F B}-\frac{k T}{e}\right) & \text { p-type }
\end{array}
$$

where $\varepsilon$ is the dielectric constant of the passive film (a value of 15.6 has been assumed for the chromium and iron oxides formed on austenitic stainless steels [52]), $\varepsilon_{0}$ is the vacuum permittivity $\left(8.85 \cdot 10^{-14} \mathrm{~F} / \mathrm{cm}\right), e$ is the electron charge $\left(1.60 \cdot 10^{-19} \mathrm{C}\right), N_{D}$ and $N_{A}$ are respectively the donor and acceptor densities, $E_{F B}$ is the flat-band potential $k$ is the Boltzmann constant $\left(1.38 \cdot 10^{-23} \mathrm{~J} / \mathrm{K}\right)$ and $T$ is the absolute temperature.

Figure 9 shows the plot of $C^{-2}$ vs. potential, $E$, for the films formed on Alloy 31 at different potentials within the passive and transpassive regions. Mott-Schottky plots reveal the existence of two or three regions, depending on the film formation potential, where a Mott-Schottky type behaviour can be observed (straight lines at low and high potentials). At potentials below $-0.85 \mathrm{~V}$ (the flat-band potential, $E_{F B}$ ), straight lines with negative slopes can be observed. These lines are more evident as the film formation potential increases, and are representative of the behaviour of a $p$-type semiconductor, whose predominant acceptor species in stainless steels are chromium vacancies, $\mathrm{V}_{\mathrm{Cr}}^{3^{\prime}}$. At potentials above $-0.85 \mathrm{~V}$, another linear region appears, with positive slopes, which 
illustrate the electrochemical behaviour of an $n$-type semiconductor, whose predominant donor species are oxygen vacancies, $\mathrm{V}_{\mathrm{O}}^{\bullet \bullet}$, and/or cation interstitials, $\mathrm{Cr}_{\mathrm{i}}^{\chi^{+}}$.

At the formation potentials of 0.1 and $0.2 \mathrm{~V}$, a change in the positive slope can be observed, indicating $n$-type semiconductivity with two kinds of donors (Figure 9). The existence of two donor levels has already been suggested for passive films on stainless steels [60-63]. In the present study, the deep donors that characterise the second linear region with positive slope at higher potentials are highly related to the formation of $\mathrm{Cr}^{6+}$ ions due to transpassivity of $\mathrm{Cr}$ species, as other authors have observed [60, 61, 64]. At formation potentials higher than $0.2 \mathrm{~V}$ there is a progressive change in the sign of the linear region slope at high potentials, going from positive to negative values. This fact indicates a modification in the electronic properties of the passive film in the transpassive region, from $n$-type to $p$-type semiconductivity, and is related to an increase in the conductivity of the film due to the solid state oxidation of $\mathrm{Cr}$ (III) to $\mathrm{Cr}(\mathrm{VI})[65,66]$. The change in the semiconducting behaviour can be explained by the generation of cation vacancies (which are electronic acceptors and $p$-type dopants) at the film/solution interface through reaction (2) [26].

According to Hakiki [50] the electronic structure of the passive films formed on stainless steels can be described by a bilayer model composed of a $n$-type outer region of iron oxide $\left(\mathrm{Fe}_{2} \mathrm{O}_{3}\right)$ and hydroxide near the solutions, and a $p$-type inner region of chromium oxide $\left(\mathrm{Cr}_{2} \mathrm{O}_{3}\right)$ near the metal. Tsuchiya [67] have also used a bilayer model to describe the semiconducting behaviour of passive films formed on $\mathrm{Fe}-\mathrm{Cr}$ alloys in sulphuric acid solutions, assuming that these passive films were composed of an outer $n$-type hydroxide layer $\mathrm{Cr}(\mathrm{OH})_{3}$ and an inner $p$-type oxide layer of $\mathrm{Cr}_{2} \mathrm{O}_{3}$. However, the 
bilayer structure of passive films formed on stainless steels has been demonstrated to be more complex [68-75]. The $n$-type outer region would be enriched in $\mathrm{Fe}^{3+}$ species, such as $\mathrm{Fe}_{2} \mathrm{O}_{3}, \mathrm{FeO}(\mathrm{OH})$ and $\mathrm{Fe}(\mathrm{OH})_{3}$, as well as $\mathrm{Cr}(\mathrm{OH})_{3}$ and $\mathrm{CrO}(\mathrm{OH})$. The $p$-type inner region would consist of an anhydrous mixed $\mathrm{Fe}-\mathrm{Cr}$ oxide, most probably with a spinel structure, e.g. $\mathrm{FeCr}_{2} \mathrm{O}_{4}$ (chromite) [69]. This spinel should be enriched in $\mathrm{Cr}$, with the octahedral sites preferentially occupied by $\mathrm{Cr}(\mathrm{III})$ and $\mathrm{Fe}(\mathrm{II})[68,71]$, or even $\mathrm{Fe}(\mathrm{III})$ [69], so its structure should be represented in a more accurate formula as $\mathrm{Fe}(\mathrm{II})\left[\mathrm{Cr}(\mathrm{III})_{\mathrm{x}} \mathrm{Fe}(\mathrm{III})_{(1-\mathrm{x})}\right]_{2} \mathrm{O}_{4}$, where $0<x \leq 1$ [69]. Nickel may also replace iron and chromium in the spinel [68].

As it has been mentioned above, at -0.3 and $-0.2 \mathrm{~V}$ the slopes of the straight lines below the $E_{F B}$ are rather small (Figure 9), though these lines are more marked at higher formation potentials. It has been reported in the literature [76-79] that the concentration of $\mathrm{Cr}$ (III) oxide in the passive films formed on stainless steels and $\mathrm{Cr}$ alloys increases with increasing formation potential, in the passive region (at higher potentials, transpassive dissolution of chromium species occurs). The increase of $\mathrm{Cr}$ (III) oxide concentration within the passive film implies a decrease in the number of cation vacancies, $\mathrm{V}_{\mathrm{Cr}}{ }^{3}$, and consequently higher negative slopes in the $p$-type semiconductivity zone below the $E_{F B}$.

The $1 / C^{2}$ vs. $E$ plots shown in Figure 9 exhibit a minimum in the flat-band potential region. Therefore, within the passive range, the capacitance should not be derived from a single space charge region, but from at least two regions [67]. In a metal/film/electrolyte system, space charge regions can be formed in the film either at the film/electrolyte interface or at the metal/film interface [80]. 
From Mott-Schottky diagrams, the passive system can be divided into three interfaces: (I) metal/inner layer; (II) inner layer/outer layer; (III) outer layer/electrolyte. Figure 10 shows a schematic representation of the energy-band model corresponding to the behaviour observed at film formation potentials within the passive region. At interfaces (I) and (III), two space charge regions develop in the inner and outer layers, respectively, depending on the applied potential. At potentials more positive than the flat-band potential $\left(E_{F B}\right)$, the conduction and valence bands bend upwards at the outer layer/electrolyte interface (III), promoting the development of a depleted space charge region, while there is an accumulation of holes at interface (I), which behaves as an ohmic contact. On the contrary, at potentials more negative than $E_{F B}$, the bands bend downwards and the situation previously described is reversed. Thus, at the outer layer/electrolyte interface (III) an accumulation of electrons occurs, with a consequent ohmic behaviour of the outer layer of the film, which converts from a semiconductor to a metal-like conductor. Therefore, the capacitance measurements performed in the potential region $E<E_{F B}$ reflect the semiconducting properties of the inner layer of the passive film. According to this model, the passive film behaves as a $p$ - $n$ heterojunction where the space charge regions are not in contact with each other, but localised at the interfaces (I) and (III).

Donor and acceptor densities $\left(N_{D}\right.$ and $\left.N_{A}\right)$ can be calculated for $n$-type and $p$-type semiconductors using equations (9a) and (9b), respectively. Table 2 shows the values of $N_{A 1}$ and $N_{D 1}$ calculated from the slopes of the linear zones below and above the $E_{F B}$ in Figure 9, respectively. Table 2 also shows the values of $N_{D 2}$, calculated from the second linear region with positive slope at the formation potentials from 0.1 to $0.25 \mathrm{~V}$, and $N_{A 2}$, calculated from the linear region with negative slope at the formation 
potentials from 0.3 to $0.4 \mathrm{~V}$. Finally, the last column of Table 2 gathers the total density of defects in the outer layer of the passive film, calculated as $N_{D 1}+N_{D 2}$ or $N_{D 1}+N_{A 2}$, depending on the semiconducting behaviour at high potentials within the transpassive region.

It can be seen from Table 2 that defects density values are of the order of $10^{20}-10^{21}$, which matches the results of studies on stainless steels $[64,71,81,82]$. In general, the values of $N_{A 1}$ and $N_{D 1}$ decrease with increasing potentials, since anodic polarisation has an annealing effect which eliminates some defects in the passive film [23]. Thus, passive films formed at low passive potentials have more disordered structures and higher defect densities than those formed at higher passive potentials. It must be remarked that the density of cation vacancies present in the inner layer of the passive film, $N_{A l}$, is always higher than the density of oxygen vacancies or cation interstitials present in the outer layer of the film, $N_{D 1}$. This result is consistent with the result obtained from the PDM diagnostic criterion concerning the relationship between $\ln i_{S S}$ and $E_{f}$, as explained above in eq. (3). This criterion has been used to identify the predominant crystallographic defect type within the passive film, which has been found to be cation vacancy. However, although cation vacancies are the main defects within the passive film and determine the $p$-type semiconductivity of the inner layer of the passive film, Mott-Schottky analysis has revealed that the outer layer of the passive film behaves as an $n$-type semiconductor, doped with oxygen vacancies and/or cation interstitials. Therefore, the diagnostic criteria provided by the PDM should be used along with the Mott-Schottky analysis to avoid possible ambiguities. 
At formation potentials above $0.1 \mathrm{~V}$, an increase in the number of defects in the outer as deep donor species $\left(N_{D 2}\right)$ and cation vacancies, $\mathrm{V}_{\mathrm{Cr}}^{3^{\prime}}$, as acceptor species $\left(N_{A 2}\right)$ according to eq. (2). Therefore, while the number of defects in the outer layer of the passive film decreases with film formation potential within the passive region, it increases dramatically at formation potentials within the transpassive region. The more defective structure of the film formed at potentials within the transpassive region can explain the lower resistance values obtained in the EIS experiments at high formation potentials (Table 1).

According to the results obtained in the Mott-Schottky analysis and to the proposed model for the electronic structure of the passive film formed on Alloy 31 (Figure 10), two space charge regions appear at the metal/inner layer and outer layer/electrolyte interfaces. The capacitance of these space charge regions, $C_{S C}$, can be obtained from the measured capacitance values using eq. (7). As it has been explained above, the capacitances of the Helmholtz layer, $C_{H}$, should not be neglected. It can be assumed that at the flat-band potential, $C_{H}$ is equal to the total measured capacitance, since no depletion layer exists at this potential and the contribution of the space charge or the passive film to the total capacitance values is negligible $[55,83]$. Thus, $C_{H}$ values were estimated to be about $20-22 \mu \mathrm{F} \mathrm{cm}^{-2}$.

The thickness of the space charge layers formed in both inner and outer regions of the passive film can be calculated from the $C_{S C}$ values determined at the formation potential (thickness of the outer layer) and at the most negative potential (thickness of the inner layer) with the formula for a parallel plane condenser [54, 84]: 


$$
C_{S C}=\frac{\varepsilon \cdot \varepsilon_{0}}{W}
$$

where $W$ is the space charge layer thickness. Table 3 gives the thickness values of the space charge layers formed on the two regions of the passive film (inner $p$-type layer and outer $n$-type layer, $W_{i}$ and $W_{o}$, respectively). In the passive region, the thickness of both layers increases with increasing formation potentials. In the transpassive region, however, the thickness of the outer layer diminishes, whereas the thickness of the inner layer remains nearly constant. These results, along with the Mott-Schottky analysis, suggest that transpassive dissolution of $\mathrm{Cr}$ species takes place mainly in the outer layer of the passive film in contact with the electrolyte. Ben-Haim and co-workers [85] observed lower values of hydroxide content for transpassive films in comparison to primary passive films on stainless steels, which indicates that the solid state oxidation of $\mathrm{Cr}(\mathrm{III})$ to $\mathrm{Cr}(\mathrm{VI})$ in the passive films formed on stainless steels takes place through the oxidation of chromium hydroxide, according to [86, 87]:

$$
\mathrm{Cr}(\mathrm{OH})_{3}(\text { film })+5 \mathrm{OH}^{-}(\text {film }) \rightarrow \mathrm{CrO}_{4}^{2-}(\text { film })+4 \mathrm{H}_{2} \mathrm{O}+3 \mathrm{e}^{-}
$$

Consequently, and according to the results obtained in the present work, it can be concluded that transpassive dissolution of Alloy 31 in the $400 \mathrm{~g} / \mathrm{l} \mathrm{LiBr}$ solution is restricted to the outer layer of the passive film, where $\mathrm{Cr}$ (III) species are in the form of $\mathrm{Cr}(\mathrm{OH})_{3}$.

The magnitude of the thickness of the space charge layers shown in Table $\mathbf{3}$ are in good agreement with the thickness of passive films formed on stainless steels, which is in the range of $1-3 \mathrm{~nm}$ [70]. The steady-state thickness of the passive film, $L_{S S}$, can be 
estimated from the sum of $W_{i}$ and $W_{o}$. Figure 11 shows the relationship between the estimated steady-state thickness of the passive film, $L_{S S}$, and the formation potential. Two regions can be clearly distinguished, corresponding to the passive and transpassive regions. There is a linear dependence between $L_{S S}$ and $E$ in both zones, although the slope of the straight line in Region I (passive region) is positive, whereas the slope of the straight line in Region II (transpassive region) is negative. In the case of Region II, the transpassive state is induced by the oxidative emission of cations from the passive film into the interface film/electrolyte, eq. (2), and by the oxidative dissolution of the outer layer of the passive film, eq. (10), resulting in a decrease of the film layer thickness (mainly the outer layer of the film) as the potential increases within the transpassive region, as other authors have observed [25, 26].

The linear dependence between $L_{S S}$ and $E$ in the passive region (Region I) is a well established experimental result in the anodic oxidation of metals $[16,18,70]$. The value of the positive slope, $1.59 \mathrm{~nm} \mathrm{~V}^{-1}$, is in good agreement with the $1-2.5 \mathrm{~nm} \mathrm{~V}^{-1}$ normally found for the passive film formation on metal and alloys [23, 26, 48, 88]. The simplified relation between formation potential, $E_{f}$, and steady-state thickness, $L_{S S}$, in the PDM is given in the following equation, for those cases where no change in the oxidation state occurs upon ejection of a cation from the passive film and at constant $\mathrm{pH}$ :

$$
L_{S S}=\frac{1-\alpha}{\varepsilon} E_{f}+B
$$

where $\alpha$ represents the polarizability of the film/electrolyte interface and $B$ is a constant. From the slope of the straight line in Region I and assuming a value of $\alpha=0.7$ [24-26], 
the mean electric field strength has been calculated to be $1.89 \cdot 10^{6} \mathrm{~V} \mathrm{~cm}^{-1}$, which is in agreement with other studies $[15,23,25,26]$.

Finally, the previous results must be discussed in terms of local breakdown of the passive film and the onset of pitting corrosion. According to the PDM [16], the breakdown of passivity occurs as a result of an enhanced flux of cation vacacies from the film/electrolyte interface (where they are formed) to the metal/film interface (where they are annihilated). This enhanced flux is envisaged to arise from the adsorption of aggressive anions (such as $\mathrm{Br}^{-}$) into oxygen vacancies at the film/electrolyte interface. If the flux of cation vacancies exceeds the rate at which they are annihilated at the metal/film interface, the excess vacancies condense at the interface. When the condensate exceeds a critical areal concentration (mol vacancies $/ \mathrm{cm}^{2}$ ), the film is detached locally from the underlying metal, its thickness decreases and film breakdown occurs. In the present study, an increase in the total number of cation vacancies $\left(N_{A l}+\right.$ $N_{A 2}$ ) has been observed at formation potentials within the transpassive region. Moreover, in the transpassive region the Warburg resistance has been found to decrease significantly, which indicates that transport of defects within the passive film is enhanced in this region, as it has been explained above. Therefore, as formation potential increases within the transpassive region, the density and transport rate of cation vacancies in the film increase, generating the necessary conditions for the rupture of the film. In fact, the transpassive region of Alloy 31 in the $400 \mathrm{~g} / \mathrm{l} \mathrm{LiBr}$ solution (Figure 2) is located at potentials below the pitting potential $\left(E_{p}=0.68 \mathrm{~V}[20]\right)$, indicating that transpassive dissolution of $\mathrm{Cr}$-containing species present in the passive film is closely related to the passive film breakdown and localised corrosion phenomena. 


\section{CONCLUSIONS}

Cation vacancies have been found to be the dominant defect in the passive films formed anodically on Alloy 31 in a $400 \mathrm{~g} / \mathrm{l} \mathrm{LiBr}$ solution at $25^{\circ} \mathrm{C}$ in both passive and transpassive regions. The steady-state passive current density, $i_{S S}$, increases significantly at potentials located on the transpassive region.

The charge transfer resistance, $R_{l}$, increases with applied formation potential within the passive region, which is indicative of the formation of a protective passive film. The Warburg resistance, $R_{W}$, remains approximately constant in the passive range, indicating that the electric field strength is independent of the applied potential, as postulated by the PDM. At formation potentials within the transpassive region, a decrease in $R_{l}$ and $R_{W}$ has been observed, which is an indication of the increasing concentration of defects in the passive film and increasing conductivity.

Mott-Schottky plots for Alloy 31 in the $400 \mathrm{~g} / \mathrm{L} \mathrm{LiBr}$ solution at $25^{\circ} \mathrm{C}$ and at formation potentials within the passive range reveal the existence of two regions where a MottSchottky type behaviour can be observed ( $n$-type semiconductor at potentials higher than $E_{F B}$ and $p$-type semiconductor at potentials lower than $\left.E_{F B}\right)$. These results can be explained considering a bilayer model of the passive film, with a $n$-type outer region enriched in $\mathrm{Fe}^{3+}$ species, such as $\mathrm{Fe}_{2} \mathrm{O}_{3}, \mathrm{FeO}(\mathrm{OH})$ and $\mathrm{Fe}(\mathrm{OH})_{3}$, as well as $\mathrm{Cr}(\mathrm{OH})_{3}$ and $\mathrm{CrO}(\mathrm{OH})$, and a $p$-type inner region made up of an anhydrous mixed $\mathrm{Fe}-\mathrm{Cr}$ oxide, most probably with a spinel structure. 
At film formation potentials within the transpassive region, a deep donor level has been observed, corresponding to the formation of $\mathrm{Cr}^{6+}$ ions due to transpassivity of $\mathrm{Cr}$ species. Above $0.2 \mathrm{~V}$ a progressive change in the linear region slope at high potentials has been observed, evidencing a change in the electronic properties of the film, from $n$ type to $p$-type semiconductivity. This change has been attributed to the increase in the concentration of cation vacancies in the outer layer of the passive film due to the oxidative emission of cations.

It has been demonstrated from Mott-Schottky analysis that cation vacancies are the preponderant defects within the passive film, confirming the results obtained by the PDM diagnostic criterion concerning the relationship $\ln i_{S S}$ vs $E_{f}$. These two methods should be used together to complement each other and to provide complete results.

The density of defects in the outer layer of the film increases and the thickness of this outer layer decreases noticeably in the transpassive region, while both parameters remain constant for the inner layer of the film. These observations suggest that the solid state oxidation of $\mathrm{Cr}(\mathrm{III})$ to $\mathrm{Cr}(\mathrm{VI})$ takes place through the oxidation of chromium hydroxide present in the outer layer of the passive film.

The thickness of the passive film is found to increase linearly with formation potentials within the passive region, while it decreases in the transpassive region. The decrease of film thickness in the transpassive region is a consequence of the oxidative emission of cations from the passive film into the film/electrolyte interface and the oxidative dissolution of the outer layer of the passive film. 


\section{ACKNOWLEDGEMENTS}

We wish express our gratitude to the Ministerio de Ciencia e Innovación (Project CTQ2009-07518), for the economical support of this research, to Thyssen Krupp for supplying the materials, and to Dr. M. Asunción Jaime for her translation assistance.

\section{REFERENCES}

[1] A. M. Papadopoulos, S. Oxizidis, N. Kyriakis. Perspectives of solar cooling in view of the developments in the air-conditioning sector, Renew. Sust. Energ. Rev. 7 (2003) 419-438.

[2] Y. Fan, L. Luo, B. Souyri. Review of solar sorption refrigeration technologies: Development and applications, Renew. Sust. Energ. Rev. 11 (2007) 17581775 .

[3] U. Desideri, S. Proietti, P. Sdringola. Solar-powered cooling systems: Technical and economic analysis on industrial refrigeration and airconditioning applications, Appl. Energ. 86 (2009) 1376-1386.

[4] P. Bermejo, F. J. Pino, F. Rosa. Solar absorption cooling plant in Seville, Sol. Energy 84 (2010) 1503-1512.

[5] A. Igual-Muñoz, J. García-Antón, J. L. Guiñón, V. Pérez-Herranz. Galvanic Study of Zinc and Copper in Lithium Bromide Solutions at Different Temperatures, Corrosion 57 (2001) 516-522.

[6] A. Igual-Muñoz, J. García-Antón, J. L. Guiñón, V. Pérez-Herranz. Corrosion Behavior and Galvanic Coupling of Stainless Steels, Titanium, and Alloy 33 in Lithium Bromide Solutions, Corrosion 59 (2003) 606-615.

[7] D. M. García-García, J. García-Antón, A. Igual-Muñoz, E. Blasco-Tamarit. Effect of cavitation on the corrosion behaviour of welded and non-welded duplex stainless steel in aqueous LiBr solutions, Corros. Sci. 48 (2006) 23802405 .

[8] E. Blasco-Tamarit, A. Igual-Muñoz, J. García-Antón, D. M. García-García. Effect of aqueous $\mathrm{LiBr}$ solutions on the corrosion resistance and galvanic corrosion of an austenitic stainless steel in its welded and non-welded condition, Corros. Sci. 48 (2006) 863-886.

[9] R. M. Fernández-Domene, E. Blasco-Tamarit, D. M. García-García, J. GarcíaAntón. Repassivation of the damage generated by cavitation on UNS N08031 
in a $\mathrm{LiBr}$ solution by means of electrochemical techniques and Confocal Laser Scanning Microscopy, Corros. Sci. 52 (2010) 3453-3464.

[10] R. M. Fernández-Domene, E. Blasco-Tamarit, D. M. García-García, J. GarcíaAntón. Thermogalvanic corrosion of Alloy 31 in different heavy brine $\mathrm{LiBr}$ solutions, Corros. Sci. 55 (2012) 40-53.

[11] E. A. Abd El Meguid, N. K. Awad. Electrochemical pitting corrosion behaviour of [alpha]-brass in $\mathrm{LiBr}$ containing solutions, Corros. Sci. 51 (2009) 1134-1139.

[12] V. Guiñón-Pina, A. Igual-Muñoz, J. García-Antón. Influence of pH on the electrochemical behaviour of a duplex stainless steel in highly concentrated LiBr solutions, Corros. Sci. 53 (2011) 575-581.

[13] Nicrofer® 3127 hMo - alloy 31: Material Data Sheet No. 4031, ThyssenKrupp VDMGmbH. (2002).

[14] C. Y. Chao, L. F. Lin, D. D. Macdonald. A Point Defect Model for Anodic Passive Films, J. Electrochem. Soc. 128 (1981) 1187-1194.

[15] D. D. Macdonald, M. Urquidi-Macdonald. Theory of Steady-State Passive Films, J. Electrochem. Soc. 137 (1990) 2395-2402.

[16] D. D. Macdonald. The Point Defect Model for the Passive State, J. Electrochem. Soc. 139 (1992) 3434-3449.

[17] D. D. Macdonald, S. R. Biaggio, H. Song. Steady-State Passive Films. Interfacial Kinetic Effects and Diagnostic Criteria, J. Electrochem. Soc. 139 (1992) 170-177.

[18] D. D. Macdonald. Passivity - the key to our metals-based civilization, Pure Appl. Chem. 71 (1999) 951-978.

[19] D. D. Macdonald. The history of the Point Defect Model for the passive state: A brief review of film growth aspects, Electrochim. Acta 56 (2011) 17611772.

[20] R. M. Fernández-Domene, E. Blasco-Tamarit, D. M. García-García, J. GarcíaAntón. Effect of Temperature on Thermogalvanic Coupling of Alloy 31 in LiBr Solutions Studied by Means of Imposed Potential Measurements, Int. J. Electrochem. Sc. 6 (2011) 3292-3300.

[21] J. Sikora, E. Sikora, D. D. Macdonald. The electronic structure of the passive film on tungsten, Electrochim. Acta 45 (2000) 1875-1883.

[22] K. Park, S. Ahn, H. Kwon. Effects of solution temperature on the kinetic nature of passive film on Ni, Electrochim. Acta 56 (2011) 1662-1669.

[23] Z. Jiang, X. Dai, H. Middleton. Investigation on passivity of titanium under steady-state conditions in acidic solutions, Mater. Chem. Phys. 126 (2011) 859-865. 
[24] D. D. Macdonald. On the tenuous nature of passivity and its role in the isolation of HLNW, J. Nucl. Mater. 379 (2008) 24-32.

[25] D. D. Macdonald, A. Sun. An electrochemical impedance spectroscopic study of the passive state on Alloy-22, Electrochim. Acta 51 (2006) 1767-1779.

[26] D. D. Macdonald, A. Sun, N. Priyantha, P. Jayaweera. An electrochemical impedance study of Alloy-22 in $\mathrm{NaCl}$ brine at elevated temperature: II. Reaction mechanism analysis, J. Electroanal. Chem. 572 (2004) 421-431.

[27] X. Zhang, J. C. Wren, I. Betova, M. Bojinov. Estimation of kinetic parameters of the passive state of carbon steel in mildly alkaline solutions from electrochemical impedance spectroscopic and X-ray photoelectron spectroscopic data, Electrochim. Acta 56 (2011) 5910-5918.

[28] M. Metikos-Hukovic, R. Babic, Z. Grubac, Z. Petrovic, N. Lajçi. High corrosion resistance of austenitic stainless steel alloyed with nitrogen in an acid solution, Corros. Sci. 53 (2011) 2176-2183.

[29] E. Sikora, D. D. Macdonald. Nature of the passive film on nickel, Electrochim. Acta 48 (2002) 69-77.

[30] S. J. Ahn, H. S. Kwon, D. D. Macdonald. Role of Chloride Ion in Passivity Breakdown on Iron and Nickel, J. Electrochem. Soc. 152 (2005) B482-B490.

[31] C. Valero Vidal, A. Igual-Muñoz. Study of the adsorption process of bovine serum albumin on passivated surfaces of CoCrMo biomedical alloy, Electrochim. Acta 55 (2010) 8445-8452.

[32] S. L. d. Assis, S. Wolynec, I. Costa. Corrosion characterization of titanium alloys by electrochemical techniques, Electrochim. Acta 51 (2006) 1815-1819.

[33] A. Igual-Muñoz, J. García-Antón, J. L. Guiñón, V. Pérez-Herranz. Inhibition effect of chromate on the passivation and pitting corrosion of a duplex stainless steel in $\mathrm{LiBr}$ solutions using electrochemical techniques, Corros. Sci. 49 (2007) 3200-3225.

[34] J. Pan, D. Thierry, C. Leygraf. Electrochemical impedance spectroscopy study of the passive oxide film on titanium for implant application, Electrochim. Acta 41 (1996) 1143-1153.

[35] A. Fattah-alhosseini, A. Saatchi, M. A. Golozar, K. Raeissi. The transpassive dissolution mechanism of 316L stainless steel, Electrochim. Acta 54 (2009) 3645-3650.

[36] D. D. Macdonald, R. Y. Liang, B. G. Pound. An Electrochemical Impedance Study of the Passive Film on Single Crystal Ni(111) in Phosphate Solutions, J. Electrochem. Soc. 134 (1987) 2981-2986.

[37] M. Sánchez, J. Gregori, M. C. Alonso, J. J. García-Jareño, F. Vicente. Anodic growth of passive layers on steel rebars in an alkaline medium simulating the concrete pores, Electrochim. Acta 52 (2006) 47-53. 
[38] M. Sánchez, J. Gregori, C. Alonso, J. J. García-Jareño, H. Takenouti, F. Vicente. Electrochemical impedance spectroscopy for studying passive layers on steel rebars immersed in alkaline solutions simulating concrete pores, Electrochim. Acta 52 (2007) 7634-7641.

[39] F. Mansfeld, L. T. Han, C. C. Lee, G. Zhang. Evaluation of corrosion protection by polymer coatings using electrochemical impedance spectroscopy and noise analysis, Electrochim. Acta 43 (1998) 2933-2945.

[40] A. Nagiub, F. Mansfeld. Evaluation of corrosion inhibition of brass in chloride media using EIS and ENA, Corros. Sci. 43 (2001) 2147-2171.

[41] M. Metikos-Hukovic, R. Babic, A. Marinovic. Spectrochemical Characterization of Benzotriazole on Copper, J. Electrochem. Soc. 145 (1998) 4045-4051.

[42] J. Bisquert, G. Garcia-Belmonte, F. Fabregat-Santiago, P. R. Bueno. Theoretical models for ac impedance of finite diffusion layers exhibiting low frequency dispersion, J. Electroanal. Chem. 475 (1999) 152-163.

[43] Z. Grubac, Z. Petrovic, J. Katic, M. Metikos-Hukovic, R. Babic. The electrochemical behaviour of nanocrystalline nickel: A comparison with polycrystalline nickel under the same experimental condition, J. Electroanal. Chem. 645 (2010) 87-93.

[44] J. R. Vilche, E. C. Bucharsky, C. A. Giúdice. Application of EIS and SEM to evaluate the influence of pigment shape and content in ZRP formulations on the corrosion prevention of naval steel, Corros. Sci. 44 (2002) 1287-1309.

[45] H. Zhang, Y. L. Zhao, Z. D. Jiang. Effects of temperature on the corrosion behavior of $13 \mathrm{Cr}$ martensitic stainless steel during exposure to $\mathrm{CO} 2$ and $\mathrm{Cl}$ environment, Mater. Lett. 59 (2005) 3370-3374.

[46] I. D. Raistrick, D. R. Franceschetti, J. R. Macdonald, in: E. Barsoukov (ed.), J. R. Macdonald (ed.), Impedance Spectroscopy. Theory, Experiment, and Applications, 2005, Ch. 2.

[47] B. Hirschorn, M. E. Orazem, B. Tribollet, V. Vivier, I. Frateur, M. Musiani. Determination on effective capacitance and film thickness from constantphase-element parameters. Electrochim. Acta 55 (2010) 6218-6227.

[48] I. Nicic, D. D. Macdonald. The passivity of Type 316L stainless steel in borate buffer solution, J. Nucl. Mater. 379 (2008) 54-58.

[49] K. Uosaki, H. Kita. Effects of the Helmholtz Layer Capacitance on the Potential Distribution at Semiconductor/Electrolyte Interface and the Linearity of the Mott-Schottky Plot, J. Electrochem. Soc. 130 (1983) 895-897.

[50] N. B. Hakiki, S. Boudin, B. Rondot, M. Da Cunha Belo. The electronic structure of passive films formed on stainless steels, Corros. Sci. 37 (1995) 1809-1822. 
[51] T. L. S. L. Wijesinghe, D. J. Blackwood. Photocurrent and capacitance investigations into the nature of the passive films on austenitic stainless steels, Corros. Sci. 50 (2008) 23-34.

[52] A. D. Paola. Semiconducting properties of passive films on stainless steels, Electrochim. Acta 34 (1989) 203-210.

[53] W. P. Gomes, D. Vanmaekelbergh. Impedance spectroscopy at semiconductor electrodes: Review and recent developments, Electrochim. Acta 41 (1996) 967-973.

[54] M. Da Cunha Belo, N. E. Hakiki, M. G. S. Ferreira. Semiconducting properties of passive films formed on nickel-base alloys type Alloy 600: influence of the alloying elements, Electrochim. Acta 44 (1999) 2473-2481.

[55] J. Amri, T. Souier, B. Malki, B. Baroux. Effect of the final annealing of cold rolled stainless steels sheets on the electronic properties and pit nucleation resistance of passive films, Corros. Sci. 50 (2008) 431-435.

[56] K. Darowicki, S. Krakowiak, P. Slepski. Selection of measurement frequency in MottSchottky analysis of passive layer on nickel, Electrochim. Acta 51 (2006) 2204-2208.

[57] D. G. Li, J. D. Wang, D. R. Chen. Influence of potentiostatic aging, temperature and $\mathrm{pH}$ on the diffusivity of a point defect in the passive film on $\mathrm{Nb}$ in an $\mathrm{HCl}$ solution, Electrochim. Acta 60 (2012) 134-146.

[58] L. Hamadou, A. Kadri, N. Benbrahim. Characterisation of passive films formed on low carbon steel in borate buffer solution $(\mathrm{pH} 9.2)$ by electrochemical impedance spectroscopy, Appl. Surf. Sci. 252 (2005) 15101519 .

[59] J. O. Bockris. Interfacial electron transfer as a significant step in photoelectrochemical reactions on some semiconductors, J. Appl. Phys. 52 (1981) 808-810.

[60] J. B. Lee, S. W. Kim. Semiconducting properties of passive films formed on $\mathrm{Fe}-\mathrm{Cr}$ alloys using capacitiance measurements and cyclic voltammetry techniques, Mater. Chem. Phys. 104 (2007) 98-104.

[61] H. J. Jang, H. S. Kwon. In situ study on the effects of Ni and Mo on the passive film formed on $\mathrm{Fe}-20 \mathrm{Cr}$ alloys by photoelectrochemical and MottSchottky techniques, J. Electroanal. Chem. 590 (2006) 120-125.

[62] M. G. S. Ferreira, N. E. Hakiki, G. Goodlet, S. Faty, A. M. P. Simoes, M. Da Cunha Belo. Influence of the temperature of film formation on the electronic structure of oxide films formed on 304 stainless steel, Electrochim. Acta 46 (2001) 3767-3776.

[63] M. F. Montemor, A. M. P. Simoes, M. G. S. Ferreira, M. D. C. Belo. The role of Mo in the chemical composition and semiconductive behaviour of oxide films formed on stainless steels, Corros. Sci. 41 (1999) 17-34. 
[64] I. Toor, J. Y. Kwon, H. S. Kwon. Effects of Si on the Repassivation Kinetics and SCC Susceptibility of Stainless Steels, J. Electrochem. Soc. 155 (2008) C495-C500.

[65] T. L. S. L. Wijesinghe, D. J. Blackwood. Electrochemical and Photoelectrochemical Characterization of the Passive Film Formed on AISI 254SMO Super-Austenitic Stainless Steel, J. Electrochem. Soc. 154 (2007) C16-C23.

[66] M. Bojinov, G. Fabricius, T. Laitinen, T. Saario, G. Sundholm. Conduction mechanism of the anodic film on chromium in acidic sulphate solutions, Electrochim. Acta 44 (1998) 247-261.

[67] H. Tsuchiya, S. Fujimoto, O. Chihara, T. Shibata. Semiconductive behavior of passive films formed on pure $\mathrm{Cr}$ and $\mathrm{Fe}-\mathrm{Cr}$ alloys in sulfuric acid solution, Electrochim. Acta 47 (2002) 4357-4366.

[68] L. Freire, M. J. Carmezim, M. G. S. Ferreira, M. F. Montemor. The passive behaviour of AISI 316 in alkaline media and the effect of pH: A combined electrochemical and analytical study, Electrochim. Acta 55 (2010) 6174-6181.

[69] T. L. S. L. Wijesinghe, D. J. Blackwood. Characterisation of passive films on 300 series stainless steels, Appl. Surf. Sci. 253 (2006) 1006-1009.

[70] C.-O. A. Olsson, D. Landolt. Passive films on stainless steels--chemistry, structure and growth, Electrochim. Acta 48 (2003) 1093-1104.

[71] M. J. Carmezim, A. M. P. Simoes, M. F. Montemor, M. Da Cunha Belo. Capacitance behaviour of passive films on ferritic and austenitic stainless steel, Corros. Sci. 47 (2005) 581-591.

[72] Z. Feng, X. Cheng, C. Dong, L. Xu, X. Li. Passivity of 316L stainless steel in borate buffer solution studied by Mott-Schottky analysis, atomic absorption spectrometry and X-ray photoelectron spectroscopy, Corros. Sci. 52 (2010) 3646-3653.

[73] S. Ningshen, U. Kamachi Mudali, V. K. Mittal, H. S. Khatak. Semiconducting and passive film properties of nitrogen-containing type $316 \mathrm{LN}$ stainless steels, Corros. Sci. 49 (2007) 481-496.

[74] M. Da Cunha Belo, B. Rondot, C. Compere, M. F. Montemor, A. M. P. Simoes, M. G. S. Ferreira. Chemical composition and semiconducting behaviour of stainless steel passive films in contact with artificial seawater, Corros. Sci. 40 (1998) 481-494.

[75] G. Lothongkum, S. Chaikittisilp, A. W. Lothongkum. XPS investigation of surface films on high $\mathrm{Cr}-\mathrm{Ni}$ ferritic and austenitic stainless steels, Appl. Surf. Sci. 218 (2003) 203-210.

[76] L. Wegrelius, F. Falkenberg, I. Olefjord. Passivation of Stainless Steels in Hydrochloric Acid, J. Electrochem. Soc. 146 (1999) 1397-1406. 
[77] A. C. Lloyd, J. J. Noël, S. McIntyre, D. W. Shoesmith. Cr, Mo and W alloying additions in $\mathrm{Ni}$ and their effect on passivity, Electrochim. Acta 49 (2004) 3015-3027.

[78] M. Uemura, T. Yamamoto, K. Fushimi, Y. Aoki, K. Shimizu, H. Habazaki. Depth profile analysis of thin passive films on stainless steel by glow discharge optical emission spectroscopy, Corros. Sci. 51 (2009) 1554-1559.

[79] N. Padhy, R. Paul, U. Kamachi Mudali, B. Raj. Morphological and compositional analysis of passive film on austenitic stainless steel in nitric acid medium, Appl. Surf. Sci. 257 (2011) 5088-5097.

[80] A. Goossens, M. Vazquez, D. D. Macdonald. The nature of electronic states in anodic zirconium oxide films part 1: The potential distribution, Electrochim. Acta 41 (1996) 35-45.

[81] N. E. Hakiki, M. Da Cunha Belo, A. M. P. Simoes, M. G. S. Ferreira. Semiconducting Properties of Passive Films Formed on Stainless Steels, J. Electrochem. Soc. 145 (1998) 3821-3829.

[82] L. Pons, M. L. Délia, R. Basséguy, A. Bergel. Effect of the semi-conductive properties of the passive layer on the current provided by stainless steel microbial cathodes, Electrochim. Acta 56 (2011) 2682-2688.

[83] N. E. Hakiki, M. Da Cunha Belo. Electronic Structure of Passive Films Formed on Molybdenum-Containing Ferritic Stainless Steels, J. Electrochem. Soc. 143 (1996) 3088-3093.

[84] J. Pan, C. Leygraf, R. F. A. Jargelius-Pettersson, J. Linden. Characterization of High-Temperature Oxide Films on Stainless Steels by ElectrochemicalImpedance Spectroscopy, Oxid. Met. 50 (1998) 431-455.

[85] M. Ben-Haim, U. Atzmony, N. Shamir. Studies of Metal-Oxygen Bonds on 18\%-Cr Stainless Steel in the Passive and Transpassive Regions by Integrated and Angle-Resolved X-Ray Photoelectron Spectroscopies, Corrosion 44 (1988) 461-464.

[86] A. R. Brooks, C. R. Clayton, K. Doss, Y. C. Lu. On the Role of Cr in the Passivity of Stainless Steel, J. Electrochem. Soc. 133 (1986) 2459-2464.

[87] I. Betova, M. Bojinov, T. Laitinen, K. Mäkelä, P. Pohjanne, T. Saario. The transpassive dissolution mechanism of highly alloyed stainless steels: II. Effect of $\mathrm{pH}$ and solution anion on the kinetics, Corrosion Science 44 (2002) 26992723.

[88] D. D. Macdonald, M. C. H. McKubre, in: E. Barsoukov (ed.), J. R. Macdonald (ed.), Impedance Spectroscopy. Theory, Experiment, and Applications, 2005, Ch. 4. 


\section{$\underline{\text { Tables captions }}$}

Table 1. Equivalent circuit parameters obtained by fitting the experimental results of EIS, for Alloy 31 in the $400 \mathrm{~g} / \mathrm{l} \mathrm{LiBr}$ solution at $25{ }^{\circ} \mathrm{C}$, at different film formation potentials within the passive and transpassive regions.

Table 2. Acceptor and donor densities for Alloy 31 in the $400 \mathrm{~g} / \mathrm{l} \mathrm{LiBr}$ solution at $25^{\circ} \mathrm{C}$, at different film formation potentials within the passive and transpassive regions.

Table 3. Thicknesses of the inner $\left(W_{i}\right)$ and outer $\left(W_{o}\right)$ space charge layers for Alloy 31 in the $400 \mathrm{~g} / \mathrm{LiBr}$ solution at $25^{\circ} \mathrm{C}$, at different film formation potentials within the passive and transpassive regions.

\section{Figures captions}

Fig. 1. Current density transients for Alloy 31 in the $400 \mathrm{~g} / \mathrm{LiBr}$ solution at $25^{\circ} \mathrm{C}$ recorded after stepping the potential from the cathodic cleaning value $(-1 \mathrm{~V})$ to several film formation potential $(-0.3,-0.1$ and 0.1 $\mathrm{V}$ within the passive region, and $0.4 \mathrm{~V}$ within the transpassive region).

Fig. 2. Potentiodynamic polarisation curve of Alloy 31 in the $400 \mathrm{~g} / 1 \mathrm{LiBr}$ solution at $25^{\circ} \mathrm{C}$. The insert shows the passive and transpassive regions with detail.

Fig. 3. Dependence of the logarithm of the steady-state passive current density, $\ln i_{S S}$, on the film formation potential for Alloy 31 in the $400 \mathrm{~g} / \mathrm{LiBr}$ solution at $25^{\circ} \mathrm{C}$.

Fig. 4. Nyquist and Bode-phase plots for Alloy 31 in the $400 \mathrm{~g} / \mathrm{L} \mathrm{LiBr}$ solution at $25^{\circ} \mathrm{C}$, at several film formation potentials $(-0.3,-0.1$ and $0.1 \mathrm{~V}$ within the passive region, and $0.4 \mathrm{~V}$ within the transpassive region).

Fig. 5. Kramers-Kronig transforms of EIS data for Alloy 31 in the $400 \mathrm{~g} / \mathrm{l} \mathrm{LiBr}$ solution at $25^{\circ} \mathrm{C}$ and at $-0.1 \mathrm{~V}$. 
Fig. 6. Representation of the equivalent circuit proposed for the interpretation of EIS spectra of Alloy 31 in the $400 \mathrm{~g} / \mathrm{l} \mathrm{LiBr}$ solution at $25^{\circ} \mathrm{C}$.

Fig. 7. Capacitance-potential curves obtained at different frequencies for Alloy 31 in the $400 \mathrm{~g} / \mathrm{LiBr}$ solution at $25^{\circ} \mathrm{C}$, scanning the potential from the film formation value of $-0.1 \mathrm{~V}$ in the negative direction.

Fig. 8. Capacitance-potential curve obtained at $5 \mathrm{kHz}$ for Alloy 31 in the $400 \mathrm{~g} / \mathrm{L} \mathrm{LiBr}$ solution at $25^{\circ} \mathrm{C}$ scanning the potential from the film formation values of $-0.1 \mathrm{~V}$ (passive region) and $0.4 \mathrm{~V}$ (transpassive region), in the negative direction.

Fig. 9. Mott-Schottky plots for Alloy 31 in the $400 \mathrm{~g} / 1 \mathrm{LiBr}$ solution at $25{ }^{\circ} \mathrm{C}$ obtained at $5 \mathrm{kHz}$ at different film formation potentials within the passive and transpassive regions.

Fig. 10. Schematic representation of the electronic energy band for the passive film formed on Alloy 31 in the $400 \mathrm{~g} / \mathrm{l} \mathrm{LiBr}$ solution at $25^{\circ} \mathrm{C}$, at formation potentials within the passive region.

Fig. 11. Estimated values of the steady-state thickness of the passive film formed on Alloy 31 surface $\left(L_{S S}\right)$ as a function of the film formation potential, in the $400 \mathrm{~g} / \mathrm{LiBr}$ solution at $25^{\circ} \mathrm{C}$. 


\begin{tabular}{|c|c|c|c|c|c|c|c|}
\hline & $\begin{array}{c}E \text { vs } \\
(\mathrm{Ag} / \mathrm{AgCl}) / \mathrm{V}\end{array}$ & $\boldsymbol{R}_{S} / \Omega \mathrm{cm}^{2}$ & $R_{1} / \mathrm{k} \Omega \mathrm{cm}^{2}$ & $C_{1} / \mu \mathrm{F} \mathrm{cm}^{-2}$ & $n_{1}$ & $R_{W} / \mathbf{k} \Omega \mathrm{cm}^{2}$ & $\chi^{2}\left(\mathbf{x 1 0 ^ { - 3 }}\right)$ \\
\hline \multirow{9}{*}{$\begin{array}{c}\text { Passive } \\
\text { region }\end{array}$} & -0.30 & $1.03 \pm 0.05$ & $(1.2 \pm 0.4) \cdot 10^{2}$ & $9.1 \pm 1.0$ & $0.93 \pm 0.01$ & $(1.3 \pm 0.2) \cdot 10^{3}$ & 6.97 \\
\hline & -0.25 & $1.06 \pm 0.05$ & $(2.2 \pm 0.8) \cdot 10^{2}$ & $7.7 \pm 0.9$ & $0.93 \pm 0.01$ & $(1.61 \pm 0.08) \cdot 10^{3}$ & 8.43 \\
\hline & -0.20 & $1.03 \pm 0.06$ & $(4.5 \pm 1.0) \cdot 10^{2}$ & $8.0 \pm 1.9$ & $0.94 \pm 0.01$ & $(1.5 \pm 0.2) \cdot 10^{3}$ & 7.96 \\
\hline & -0.15 & $1.12 \pm 0.05$ & $(5.2 \pm 1.4) \cdot 10^{2}$ & $7.7 \pm 2.0$ & $0.93 \pm 0.01$ & $(1.6 \pm 0.3) \cdot 10^{3}$ & 5.60 \\
\hline & -0.10 & $1.02 \pm 0.01$ & $(8.2 \pm 1.3) \cdot 10^{2}$ & $7.0 \pm 0.1$ & $0.93 \pm 0.01$ & $(1.14 \pm 0.07) \cdot 10^{3}$ & 6.44 \\
\hline & -0.05 & $1.09 \pm 0.06$ & $(8.5 \pm 0.3) \cdot 10^{2}$ & $7.8 \pm 0.3$ & $0.94 \pm 0.01$ & $(1.5 \pm 0.2) \cdot 10^{3}$ & 7.34 \\
\hline & 0 & $1.04 \pm 0.04$ & $(9.0 \pm 1.1) \cdot 10^{2}$ & $7.8 \pm 0.2$ & $0.94 \pm 0.01$ & $(1.3 \pm 0.2) \cdot 10^{3}$ & 7.54 \\
\hline & 0.05 & $1.09 \pm 0.11$ & $(9.1 \pm 1.2) \cdot 10^{2}$ & $7.6 \pm 0.1$ & $0.93 \pm 0.01$ & $(1.4 \pm 0.2) \cdot 10^{3}$ & 5.02 \\
\hline & 0.10 & $1.06 \pm 0.07$ & $(7.9 \pm 0.8) \cdot 10^{2}$ & $7.5 \pm 0.4$ & $0.93 \pm 0.01$ & $(0.87 \pm 0.09) \cdot 10^{3}$ & 8.96 \\
\hline \multirow{6}{*}{$\begin{array}{c}\text { Transpassive } \\
\text { region }\end{array}$} & 0.15 & $1.05 \pm 0.11$ & $(6.0 \pm 1.0) \cdot 10^{2}$ & $6.5 \pm 2.3$ & $0.90 \pm 0.02$ & $(1.0 \pm 0.2) \cdot 10^{3}$ & 5.00 \\
\hline & 0.20 & $1.13 \pm 0.06$ & $(5.6 \pm 0.5) \cdot 10^{2}$ & $8.5 \pm 1.1$ & $0.91 \pm 0.01$ & $(0.39 \pm 0.07) \cdot 10^{3}$ & 7.37 \\
\hline & 0.25 & $1.18 \pm 0.05$ & $(4.9 \pm 0.7) \cdot 10^{2}$ & $7.5 \pm 0.6$ & $0.88 \pm 0.02$ & $(0.42 \pm 0.09) \cdot 10^{3}$ & 3.95 \\
\hline & 0.30 & $1.02 \pm 0.08$ & $(4.2 \pm 0.7) \cdot 10^{2}$ & $8.0 \pm 2.1$ & $0.88 \pm 0.01$ & $(0.37 \pm 0.07) \cdot 10^{3}$ & 3.28 \\
\hline & 0.35 & $0.96 \pm 0.03$ & $(3.8 \pm 0.5) \cdot 10^{2}$ & $8.2 \pm 0.9$ & $0.87 \pm 0.02$ & $(0.26 \pm 0.09) \cdot 10^{3}$ & 3.24 \\
\hline & 0.40 & $1.07 \pm 0.05$ & $(3.5 \pm 0.9) \cdot 10^{2}$ & $12.5 \pm 0.8$ & $0.90 \pm 0.01$ & $(0.22 \pm 0.05) \cdot 10^{3}$ & 6.35 \\
\hline
\end{tabular}




\begin{tabular}{|c|c|c|c|c|c|}
\hline$E$ vs (Ag/AgCl)/mV & $N_{A I} / 10^{20} \mathrm{~cm}^{-3}$ & $N_{D 1} / 10^{20} \mathrm{~cm}^{-3}$ & $N_{A 2} / 10^{20} \mathrm{~cm}^{-3}$ & $N_{D 2} / 10^{20} \mathrm{~cm}^{-3}$ & $N V_{\text {outer }} / 10^{20} \mathrm{~cm}^{-3}$ \\
\hline-0.30 & $43 \pm 8$ & $4.0 \pm 0.1$ & --- & --- & $4.0 \pm 0.1$ \\
\hline-0.25 & $22 \pm 5$ & $3.9 \pm 0.3$ & $\begin{array}{ll}--- \\
\end{array}$ & --- & $3.9 \pm 0.3$ \\
\hline-0.20 & $17 \pm 3$ & $3.9 \pm 0.2$ & --- & --- & $3.9 \pm 0.2$ \\
\hline-0.15 & $17 \pm 6$ & $3.8 \pm 0.3$ & $\begin{array}{ll}--- \\
\end{array}$ & $\begin{array}{ll}-- \\
\end{array}$ & $3.8 \pm 0.3$ \\
\hline-0.10 & $10 \pm 1$ & $3.8 \pm 0.2$ & --- & $\begin{array}{ll}-- \\
\end{array}$ & $3.8 \pm 0.2$ \\
\hline-0.05 & $10 \pm 1$ & $3.8 \pm 0.1$ & --- & --- & $3.80 \pm 0.1$ \\
\hline 0.00 & $7 \pm 2$ & $3.8 \pm 0.5$ & $\begin{array}{ll}-- \\
\end{array}$ & --- & $3.80 \pm 0.5$ \\
\hline 0.05 & $8 \pm 1$ & $4.0 \pm 0.4$ & $\begin{array}{ll}-- \\
\end{array}$ & --- & $4.0 \pm 0.4$ \\
\hline 0.10 & $8.2 \pm 0.5$ & $3.8 \pm 0.4$ & $\begin{array}{ll}-- \\
\end{array}$ & $10 \pm 1$ & $14 \pm 1$ \\
\hline 0.15 & $5.8 \pm 0.1$ & $3.3 \pm 0.2$ & --- & $11 \pm 2$ & $15 \pm 2$ \\
\hline 0.20 & $8.2 \pm 0.5$ & $3.9 \pm 0.3$ & --- & $26 \pm 4$ & $29 \pm 4$ \\
\hline 0.25 & $5.3 \pm 0.4$ & $2.9 \pm 0.3$ & --- & $39 \pm 6$ & $42 \pm 6$ \\
\hline 0.30 & $5.7 \pm 0.4$ & $3.0 \pm 0.3$ & $39 \pm 11$ & --- & $42 \pm 11$ \\
\hline 0.35 & $5.4 \pm 0.3$ & $2.9 \pm 0.2$ & $26 \pm 8$ & --- & $29 \pm 8$ \\
\hline 0.40 & $7.2 \pm 0.2$ & $3.1 \pm 0.1$ & $13 \pm 3$ & --- & $16 \pm 3$ \\
\hline
\end{tabular}




\begin{tabular}{|c|c|c|c|}
\hline & $\boldsymbol{E}$ vs $(\mathbf{A g} / \mathbf{A g C l}) / \mathbf{m V}$ & $\boldsymbol{W}_{\boldsymbol{i}} / \mathrm{nm}$ & $\boldsymbol{W}_{\boldsymbol{o}} / \mathrm{nm}$ \\
\hline \multirow{4}{*}{ Passive region } & -0.30 & --- & $0.74 \pm 0.03$ \\
\cline { 2 - 4 } & -0.25 & $0.12 \pm 0.05$ & $0.82 \pm 0.03$ \\
\cline { 2 - 4 } & -0.20 & $0.13 \pm 0.04$ & $0.84 \pm 0.04$ \\
\cline { 2 - 4 } & -0.15 & $0.20 \pm 0.07$ & $0.87 \pm 0.01$ \\
\cline { 2 - 4 } & -0.10 & $0.23 \pm 0.06$ & $0.88 \pm 0.02$ \\
\cline { 2 - 4 } Transpassive & -0.05 & $0.28 \pm 0.05$ & $0.91 \pm 0.03$ \\
\cline { 2 - 4 } region & 0.00 & $0.34 \pm 0.05$ & $0.92 \pm 0.04$ \\
\cline { 2 - 4 } & 0.05 & $0.52 \pm 0.01$ & $0.95 \pm 0.01$ \\
\cline { 2 - 4 } & 0.10 & $0.39 \pm 0.03$ & $0.97 \pm 0.02$ \\
\cline { 2 - 4 } & 0.15 & $0.46 \pm 0.07$ & $0.94 \pm 0.12$ \\
\cline { 2 - 4 } & 0.20 & $0.45 \pm 0.04$ & $0.82 \pm 0.09$ \\
\cline { 2 - 4 } & 0.25 & $0.36 \pm 0.02$ & $0.76 \pm 0.10$ \\
\cline { 2 - 4 } & 0.30 & $0.41 \pm 0.07$ & $0.64 \pm 0.03$ \\
\cline { 2 - 4 } & 0.35 & $0.45 \pm 0.03$ & $0.61 \pm 0.03$ \\
\hline \multirow{4}{*}{} & 0.40 & $0.46 \pm 0.04$ & $0.37 \pm 0.02$ \\
\hline
\end{tabular}




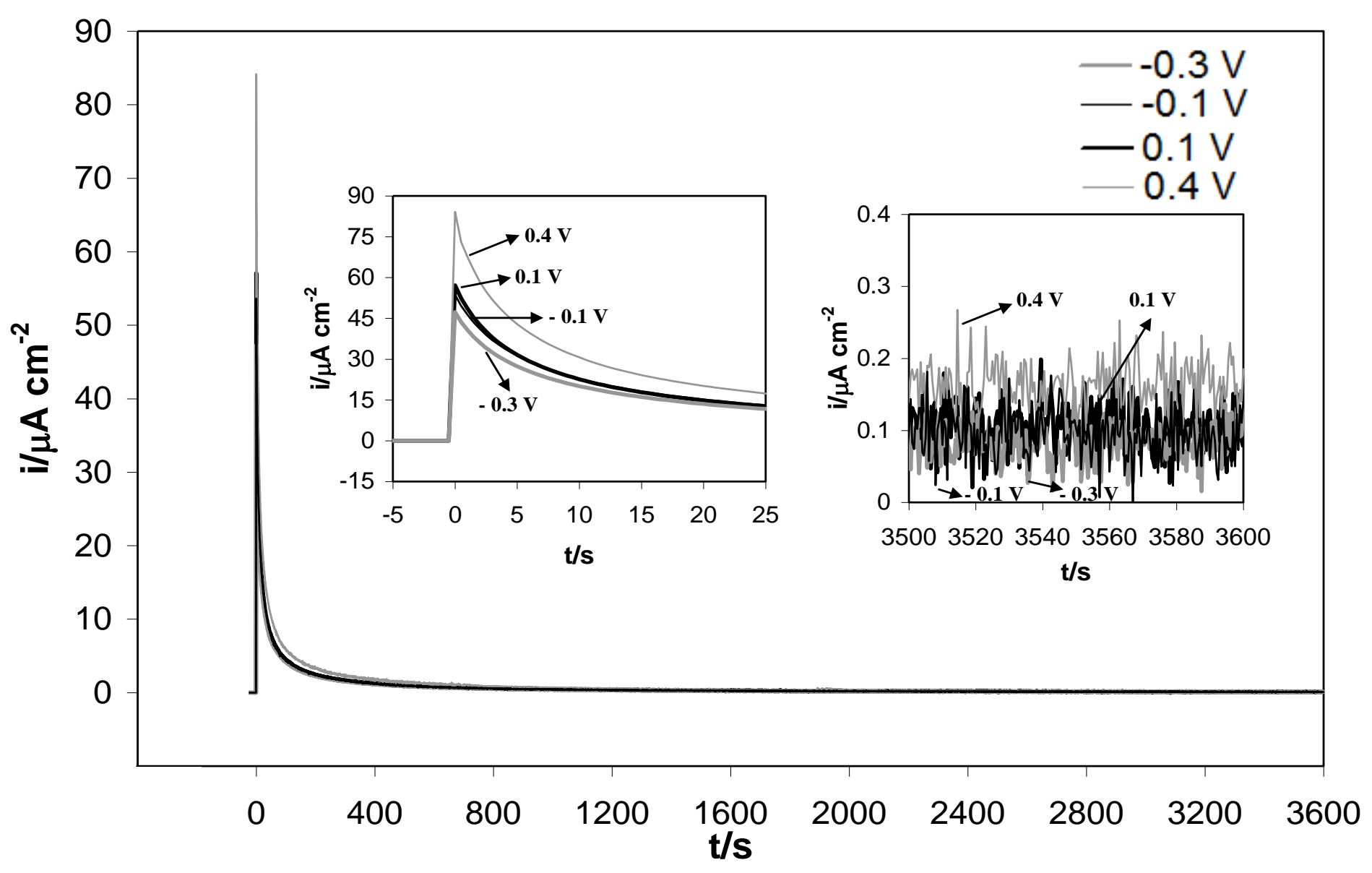


Figure 2

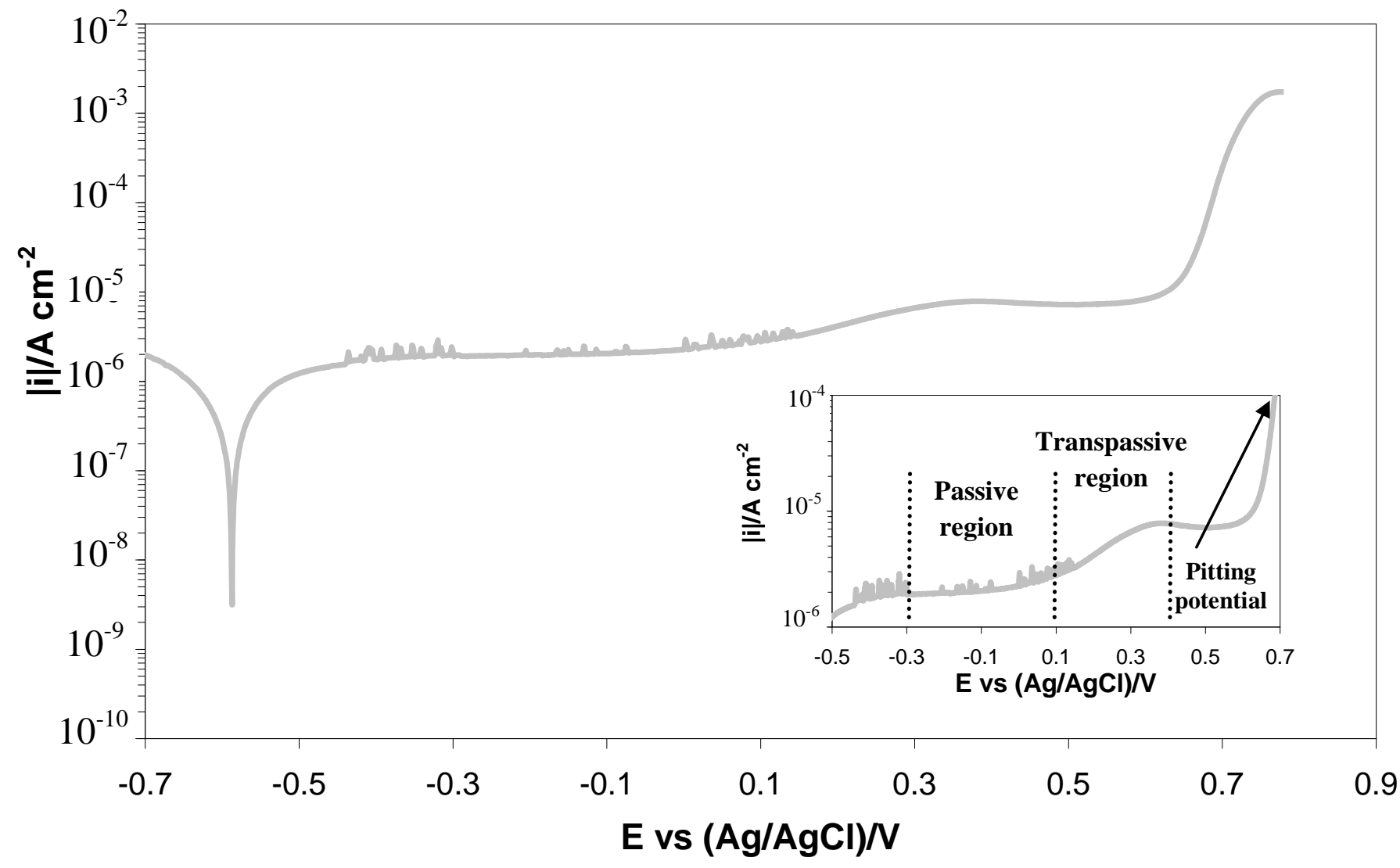




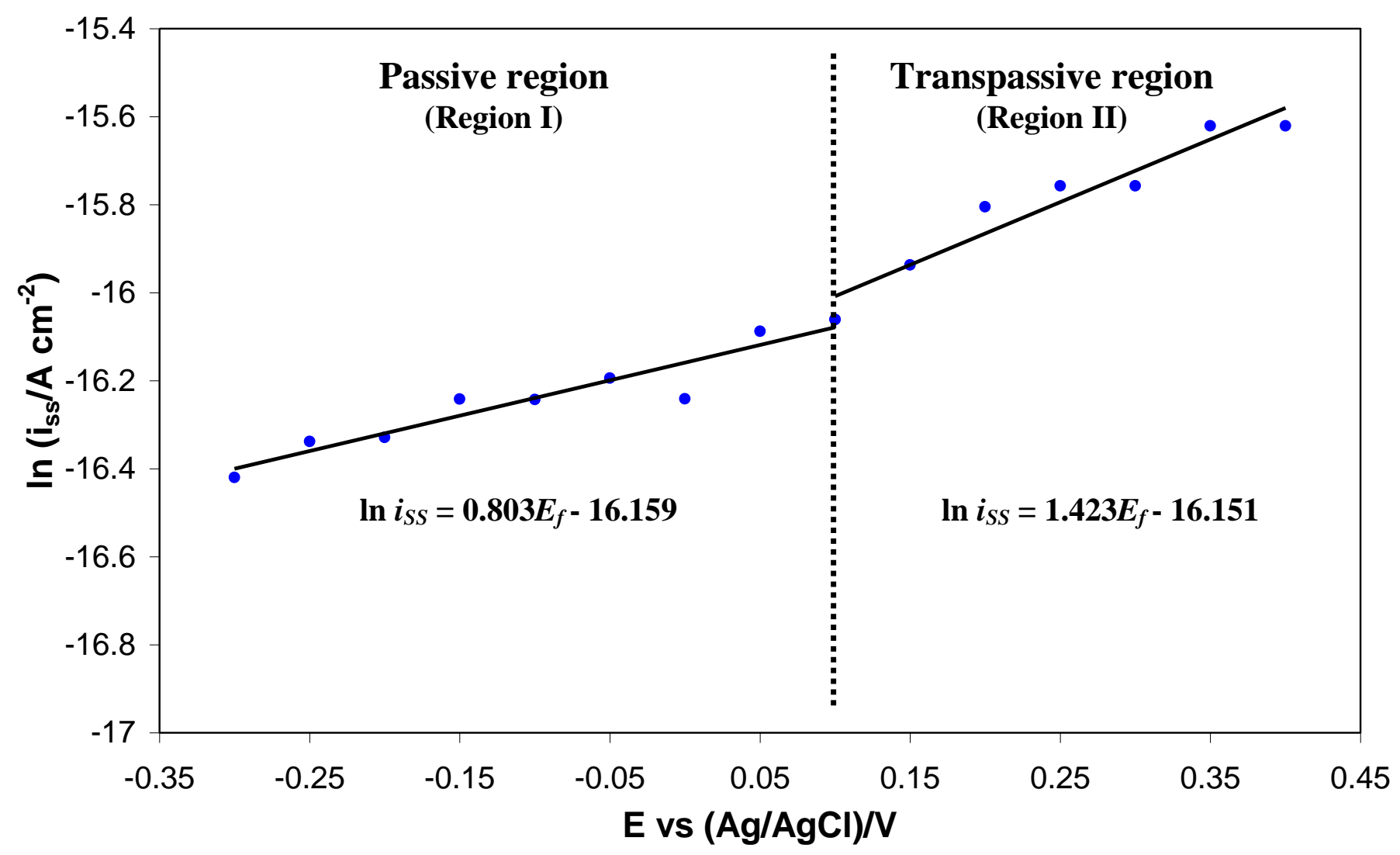




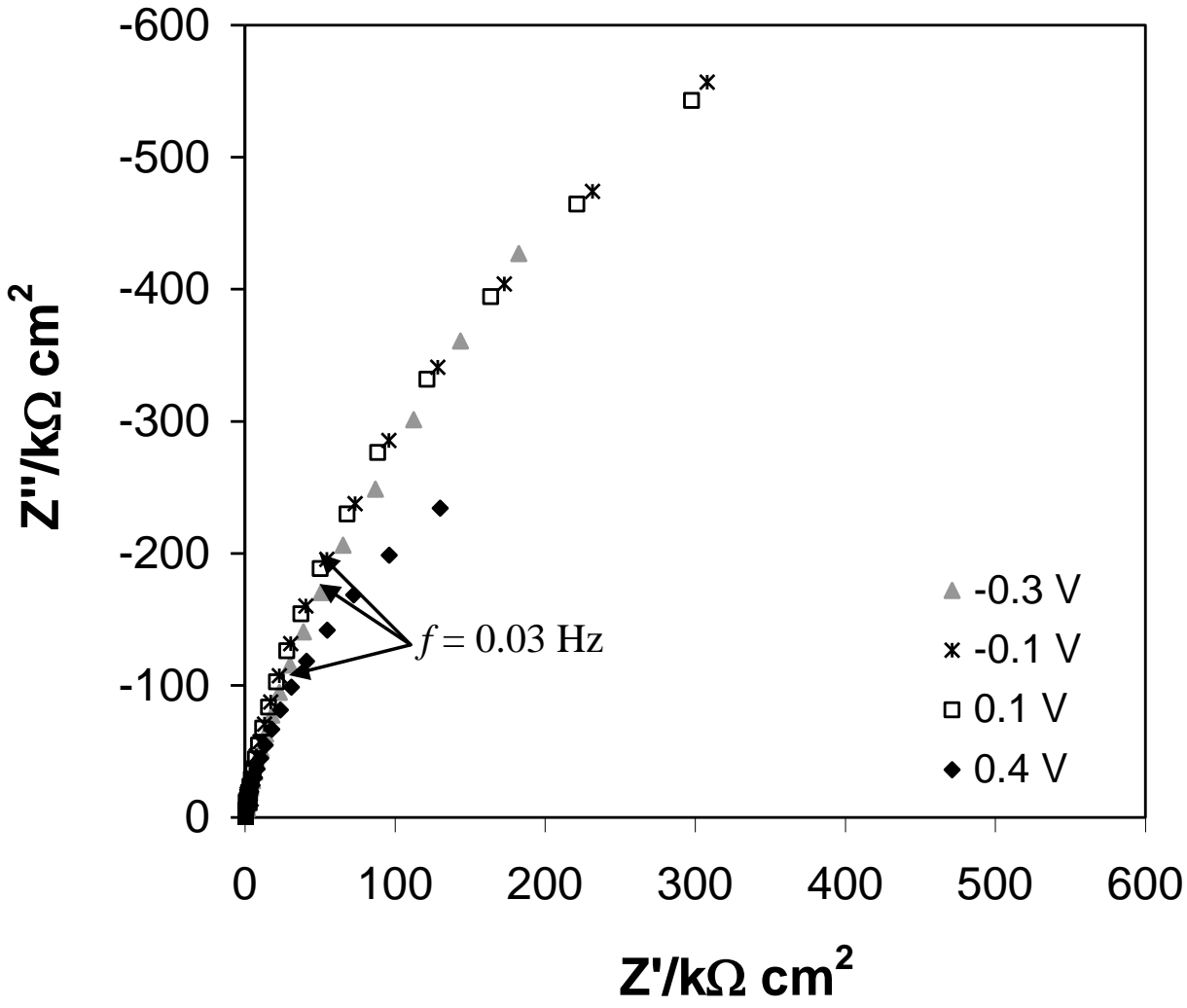

(a)

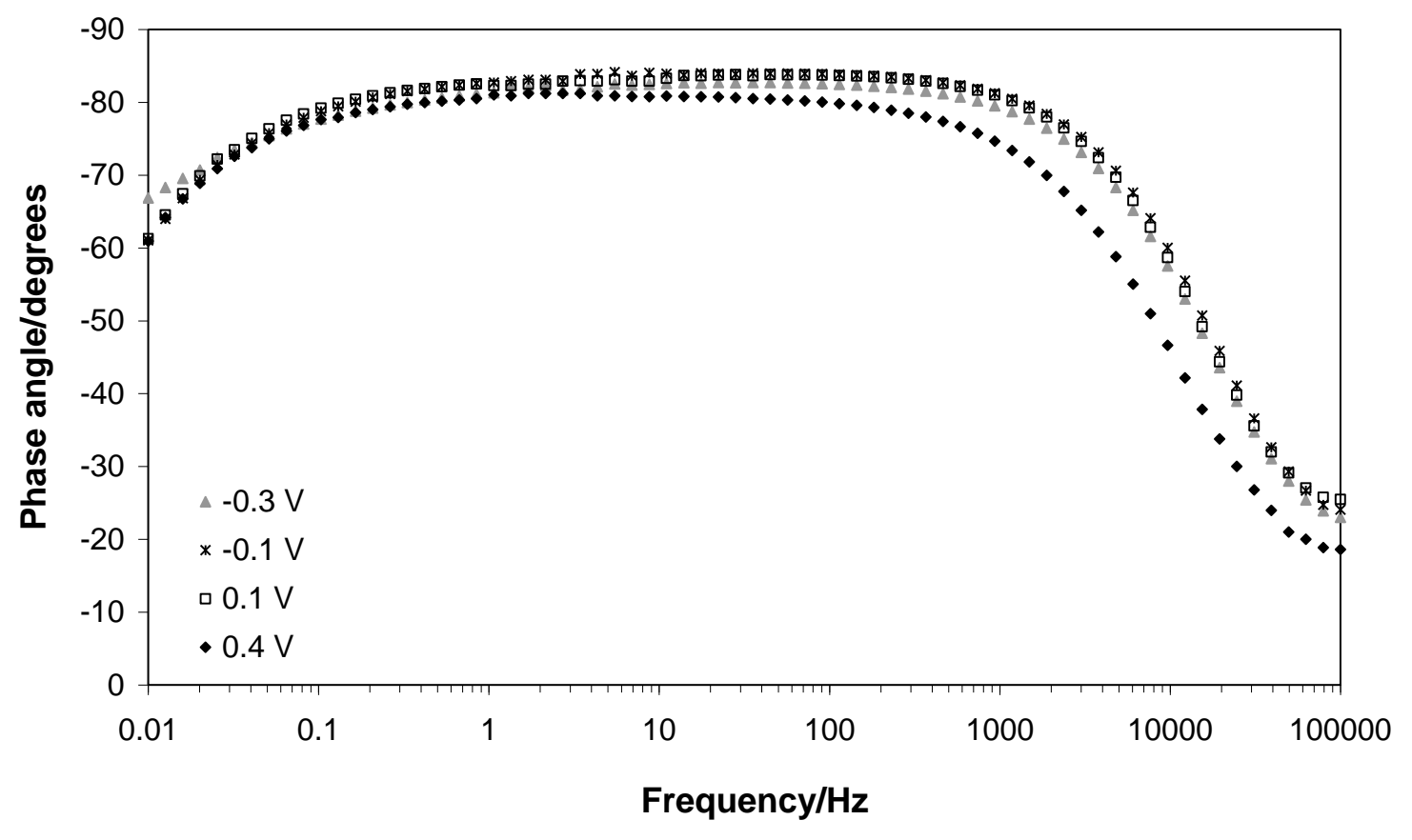

(b) 


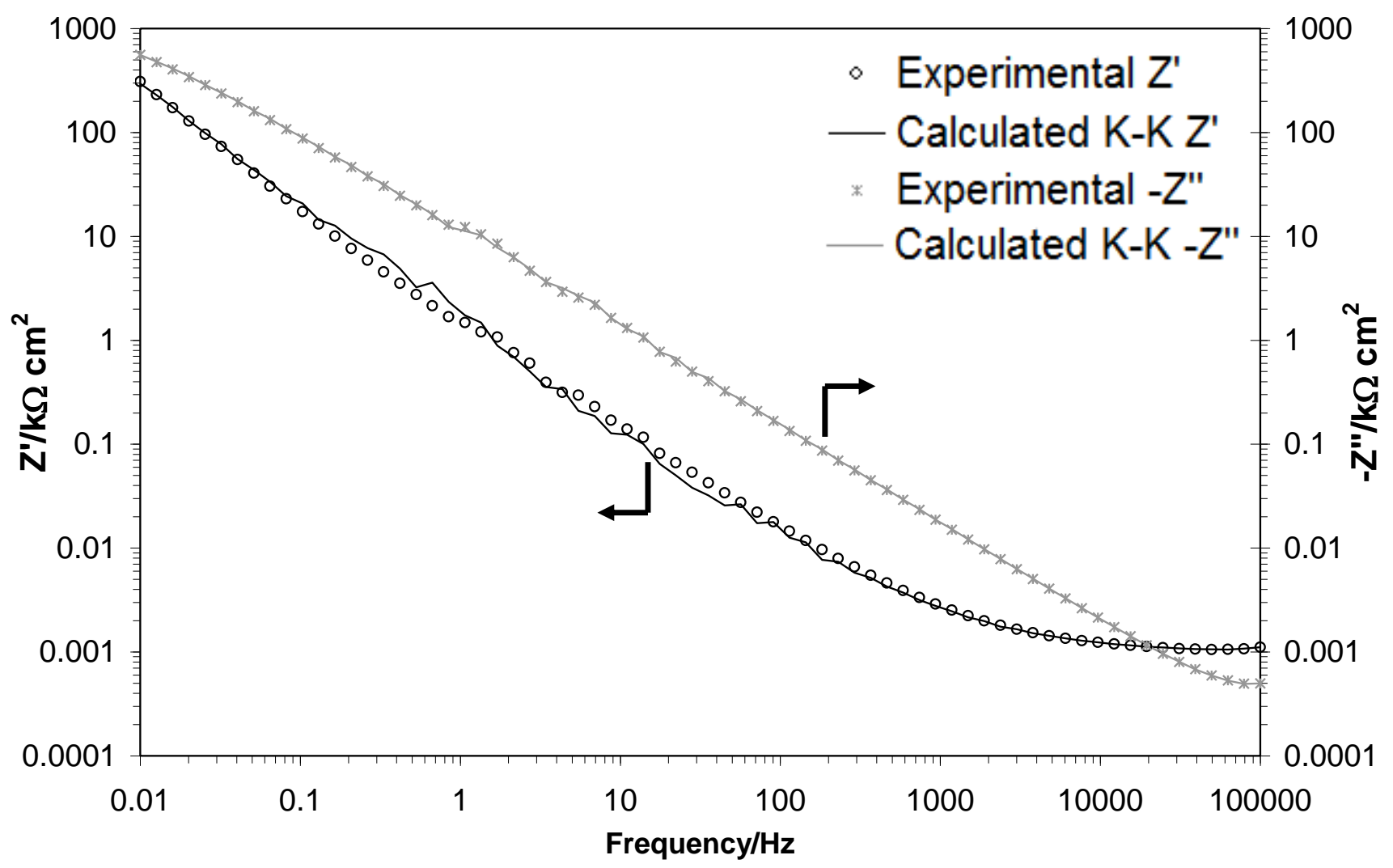




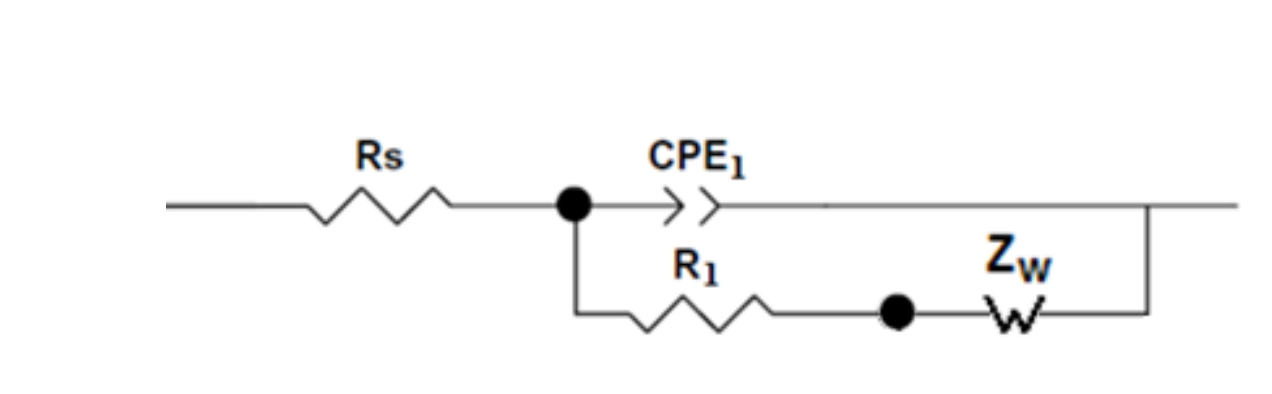

Figure 6

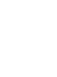

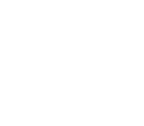

(1)<smiles>C1CCCC1</smiles><smiles>C1CCCC1</smiles><smiles>C1CCCC1</smiles><smiles>[CH]CC</smiles><smiles>[CH]=C</smiles><smiles>C1CCCC1</smiles>

.

. .
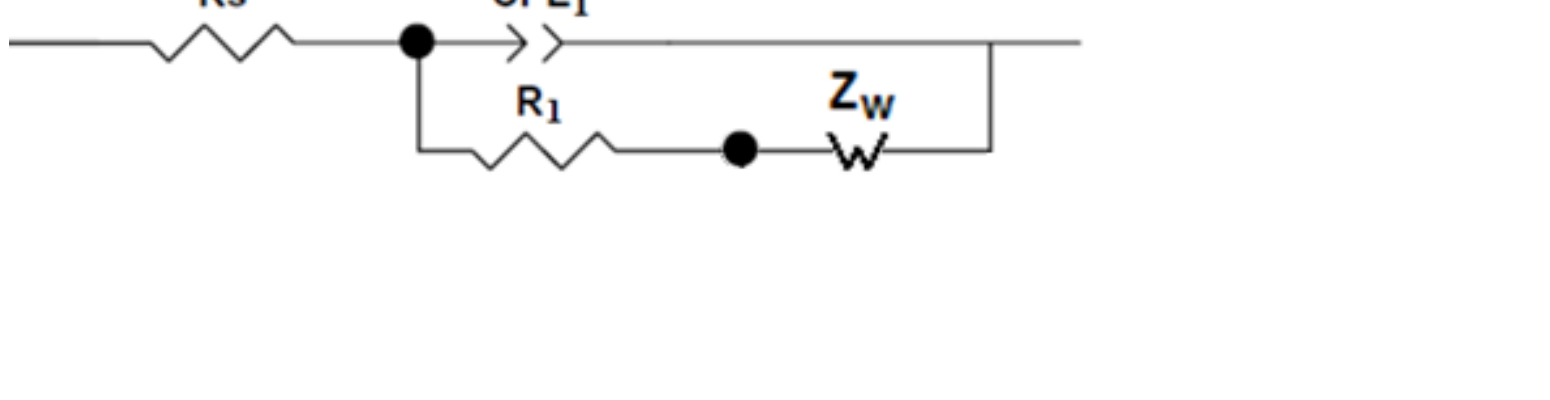

.
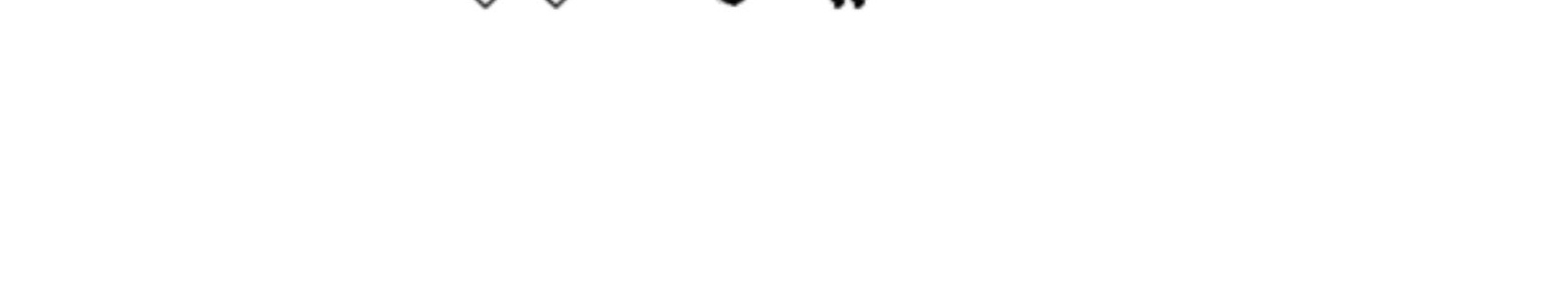
. 


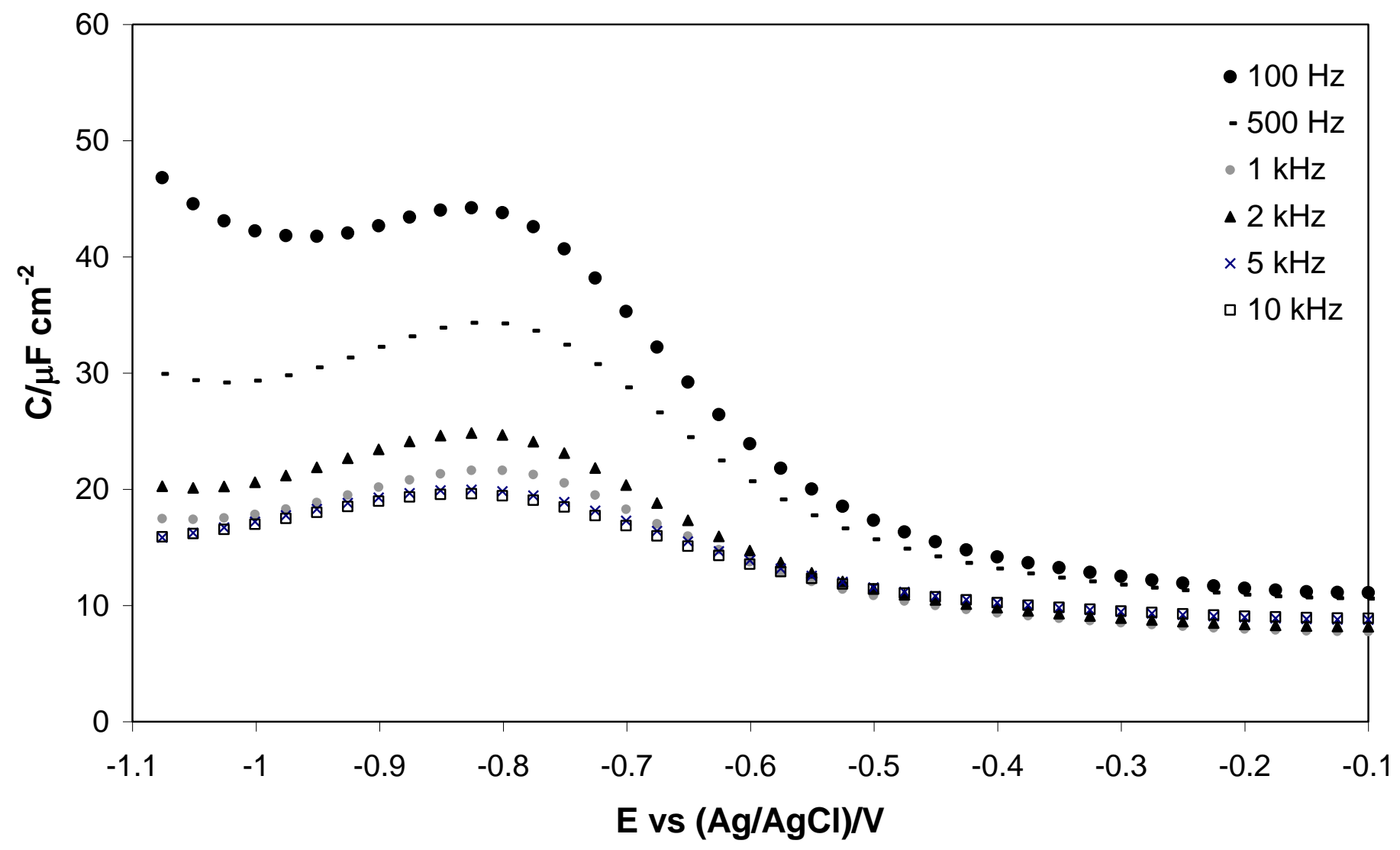


Figure 8

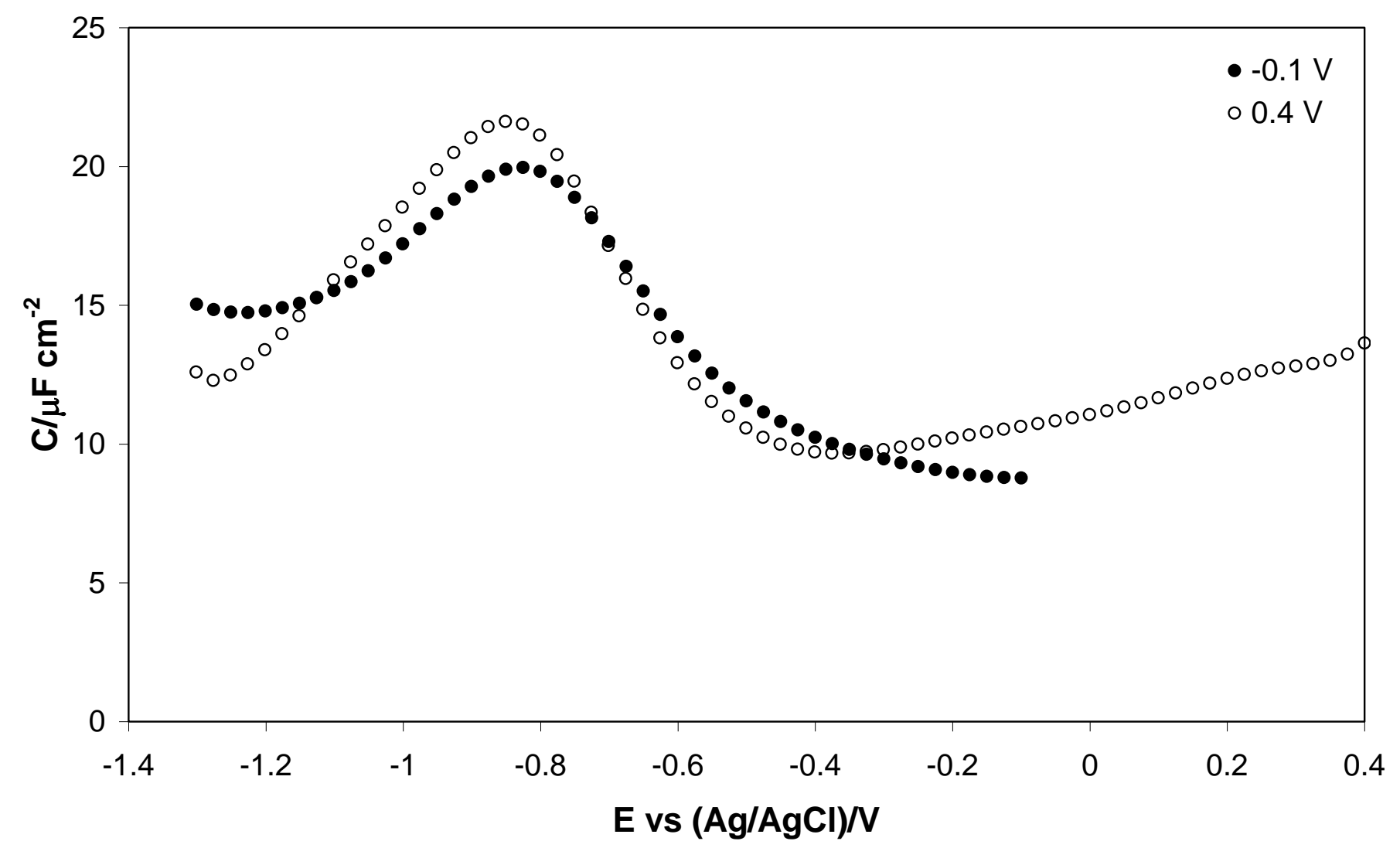




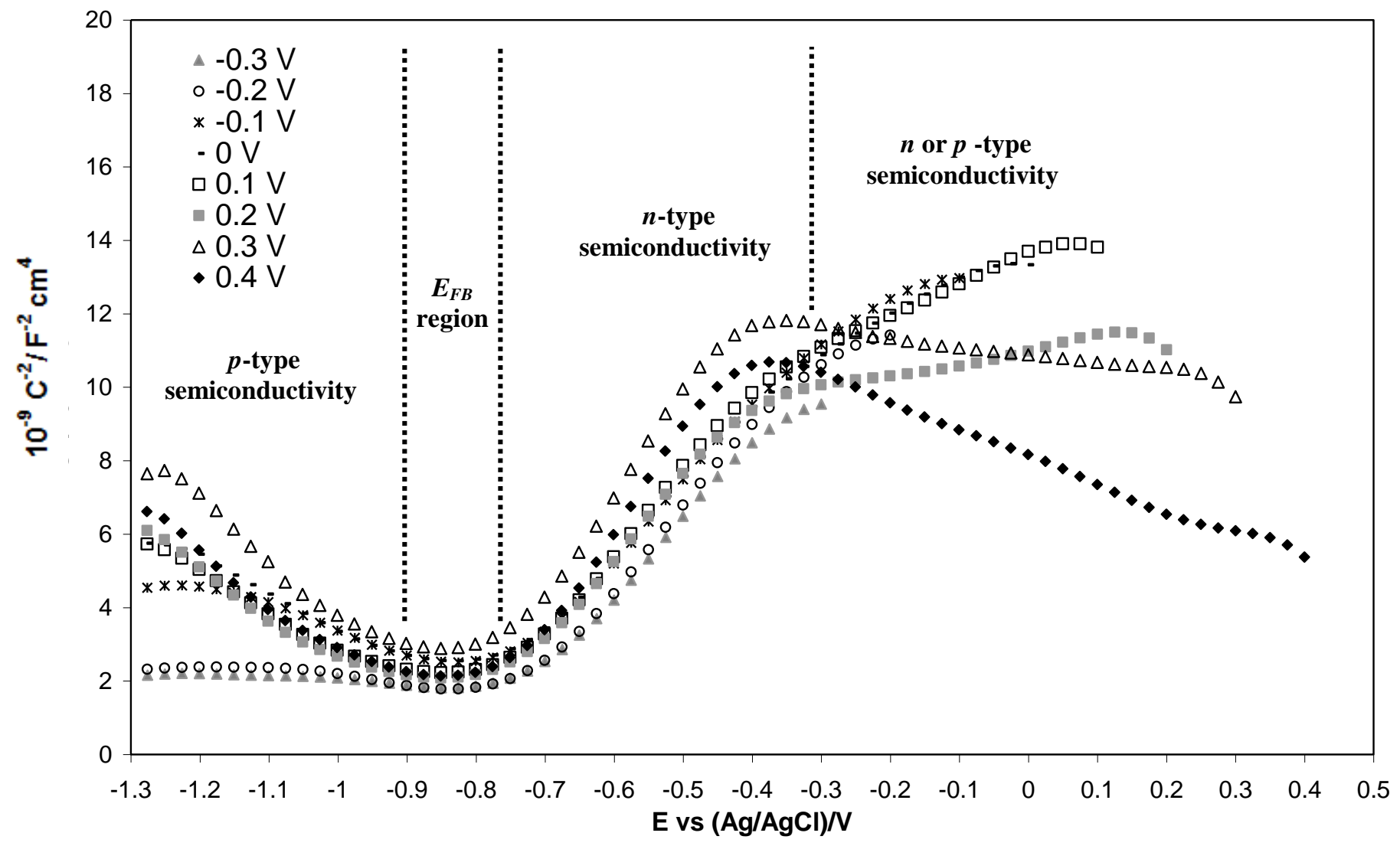




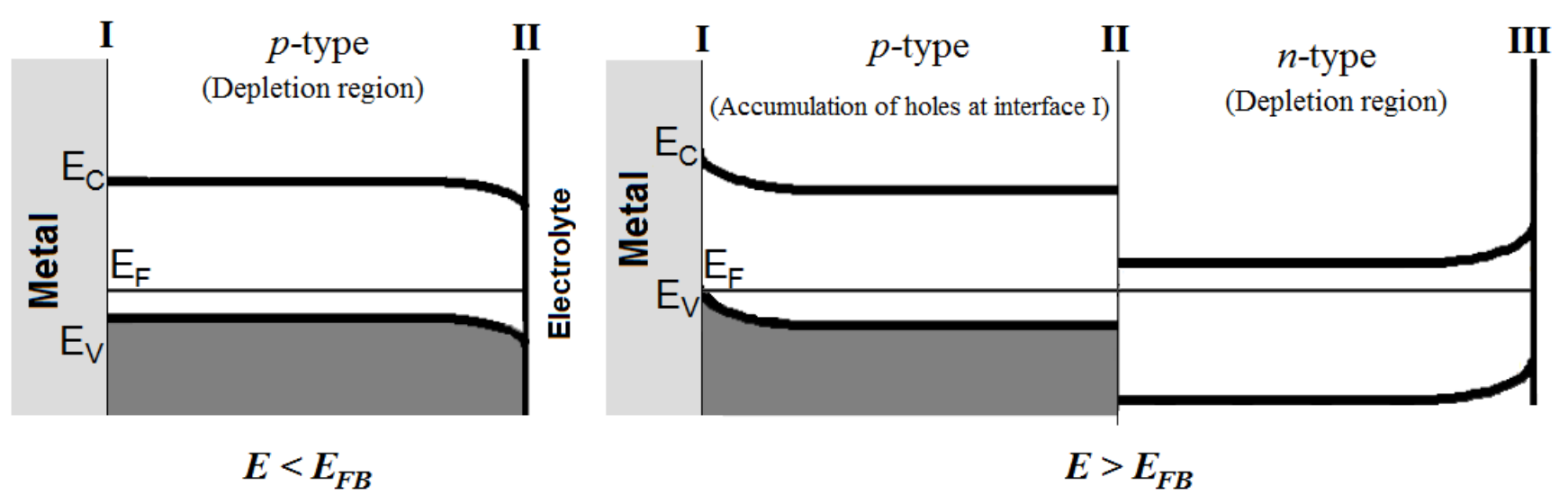




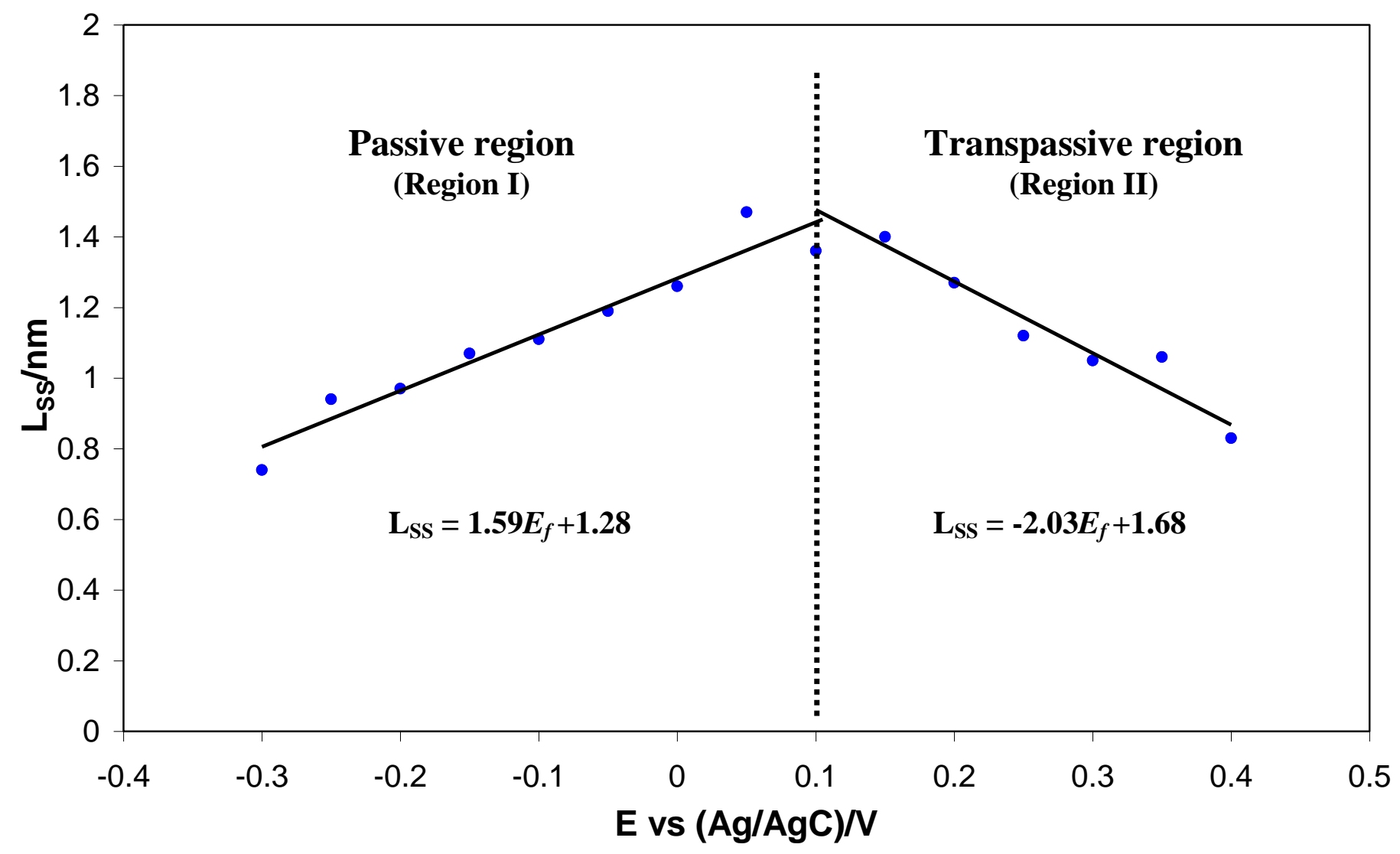

